Review

\title{
Sustainable Construction Investment, Real Estate Development, and COVID-19: A Review of Literature in the Field
}

\author{
Arturas Kaklauskas ${ }^{1, *}$, Edmundas Kazimieras Zavadskas ${ }^{2, * \mathbb{D}}$, Natalija Lepkova ${ }^{1}$ (D), Saulius Raslanas ${ }^{1}$, \\ Kestutis Dauksys ${ }^{1}$, Ingrida Vetloviene ${ }^{2}$ and Ieva Ubarte ${ }^{2}$ \\ 1 Department of Construction Management and Real Estate, Vilnius Gediminas Technical University, \\ LT-10223 Vilnius, Lithuania; natalija.lepkova@vilniustech.lt (N.L.); saulius.raslanas@vilniustech.lt (S.R.); \\ kestutis.dauksys@stud.vgtu.lt (K.D.) \\ 2 Institute of Sustainable Construction, Vilnius Gediminas Technical University, LT-10223 Vilnius, Lithuania; \\ ingrida.vetloviene@vilniustech.lt (I.V.); ieva.ubarte@vilniustech.lt (I.U.) \\ * Correspondence: arturas.kaklauskas@vilniustech.lt (A.K.); edmundas.zavadskas@vilniustech.lt (E.K.Z.)
}

check for updates

Citation: Kaklauskas, A.; Zavadskas, E.K.; Lepkova, N.; Raslanas, S.;

Dauksys, K.; Vetloviene, I.; Ubarte, I. Sustainable Construction Investment, Real Estate Development, and COVID-19: A Review of Literature in the Field. Sustainability 2021, 13, 7420 https://doi.org/10.3390/su13137420

Academic Editors: Sebastian Kot and Mariusz Urbański

Received: 7 June 2021

Accepted: 28 June 2021

Published: 2 July 2021

Publisher's Note: MDPI stays neutral with regard to jurisdictional claims in published maps and institutional affiliations.

Copyright: (c) 2021 by the authors. Licensee MDPI, Basel, Switzerland. This article is an open access article distributed under the terms and conditions of the Creative Commons Attribution (CC BY) license (https:// creativecommons.org/licenses/by/ $4.0 /)$.
Abstract: Aspects of sustainable construction investment and real estate development (CIRED) and their interrelations during the period pre-, intra-, and post-COVID-19, are presented in the research. Applications of the topic model, environmental psychology theory, building life cycle method, and certain elements of bibliometrics, webometrics, article level metrics, altmetrics, and scientometrics make it possible to perform a quantitative analysis on CIRED. The CIRED topic model was developed in seven steps. This paper aims to present a literature review on CIRED throughout the pandemic and to look at the responses from the real estate and construction sector. This sector is a field that appears to be rapidly expanding, judging from the volume of current research papers. This review focuses on last year's leading peer-reviewed journals. A combination of various keywords was applied for the review and the criteria for paper selections included construction investment, real estate development, civil engineering, COVID-19, and sustainability, as well as residential, industrial, commercial, land, and special purpose real estate, along with their risks, strategies, and trends. The articles reviewed for this paper, which analyzes three hypotheses, look at pre-, intra-, and postpandemic CIRED. The three hypotheses were validated by analyzing scientific publications from around the world. Two innovative elements make this study stand out among the most advanced research on pre-, intra-, and post-pandemic CIRED. The first of the two innovations is the integrated analysis of the COVID-19 pandemic, COVID-19-related national policies, and business investment strategies relevant to CIRED and the interests of investors as well as on the impact a CIRED policy and investors make on the spread of COVID-19. In addition, this research demonstrates a marked increase in the effectiveness of a CIRED analysis, when the life cycle of a CIRED, the involved stakeholders with their own individual interests, the COVID-19 situation, and the external micro-, meso-, and macro-environments are covered comprehensively as a single entity.

Keywords: construction investments; real estate development; sustainability; COVID-19 pandemic; construction and real estate markets; risk and strategies; trends; review

\section{Introduction}

The consumption figures by buildings around the world are some $30-40 \%$ per year [1]. Another study conducted by McAuley and Behan [2] showed that consumption of minerals taken from natural resources by the construction industry reaches as high as 50\%. Such consumption produces around 33\% of atmospheric $\mathrm{CO}_{2}$, which accounts for $40 \%$ of all energy coming from construction as well as from building operations globally. Meanwhile Petri et al. [3] report that the building sector of the EU accounts for over $40 \%$ of the energy and $\mathrm{CO}_{2}$ emissions throughout Europe. Leading in total global energy consumption is the building sector at around $30-40 \%$ of the total, according to Garshasbi and Santamouris [4]. 
A drop of some $3 \%$ worldwide in real gross domestic product (GDP) is expected by the International Monetary Fund (IMF). This constitutes a 5.9 percentage increase on the 2019 growth rate of 2.9 percent. The construction industry is bound to respond differently respective to the global region of operations. The United States now faces massive job losses in construction as well as in other sectors. Meanwhile, construction is expected to shrink in Southern European markets over a $60-70 \%$ range. In contrast, the economy of China, which includes the construction sector, has rebounded for the most part, indicating improved conditions. The data has shown an upswing since around last March/April [5].

The first wave of the COVID-19 crisis in the euro area resulted in construction companies operating at an estimated $25 \%$ to $30 \%$ below normal capacity. This was the period when communities were placed under maximally strict lockdowns. Nonetheless, conditions across the EU were very varied. Therefore, when operations were again allowed in the building industries, companies faced numerous difficulties. Apparently, the lockdowns and travel bans had caused labor deficiencies, breakdowns of supply chains resulting in construction material shortages, and strengthened health and security procedures that raised costs [6]. The first wave had impacted the construction labor market very greatly, especially due to temporary layoffs and reduced hours. The EU construction sector indicated a greater than $20 \%$ risk rate of experiencing such temporary layoffs and/or reduced hours in Q2 of 2020 [7].

The expectation regarding the effect brought by the second wave considered the time factor for adjustments to be made by firms regarding their security, which would lessen problems due to lessons learned. Furthermore, lockdowns were now better defined, so expectations were that supply chains had adjusted and shortages of inputs had been eliminated. It was thought companies would now have better security than they did under Spring 2020 conditions during the first wave [8]. The recovery in the industry showed a $97.5 \%$ rebound compared to the pre-crisis level during February 2020 regarding building production levels in November 2020 [9]. There was a V-shape to the overall recovery of the construction sector. However, total recovery of the industry back to pre-crisis levels during 2019 are not expected prior to 2023 [10]. Nonetheless, the recovery will differ considerably from state to state by speed and intensity due to the varied effect of the pandemic on industries operating in different states [11].

Many new publications on COVID-19 have appeared within the public-at-large since 2020. The effects from the pandemic hit the field of construction investment strategies, in addition to many other economic sectors. Rapid changes in behavior among investors appeared during the pandemic, becoming apparent in the construction sector and others. Remote work (meaning working from home) sparked greater demand for larger apartments/houses that would better accommodate the combining of work and personal lives within one facility. The impact on the retail sector is an upswing in demand for warehouses. Meanwhile, the administrative services sector faces radical changes in demand for operational space, which consequently launches an economy involving work sphere rearrangements.

This article provides the evidence of investments in construction behavior change due to the influence of COVID-19. By analyzing recent research, it can be seen that COVID-19 had a great impact on different types of property in different ways. The application of new technologies helps to solve a lot of problems that occurred during the COVID-19 period. This paper observes the future changes in the field of real estate, including various asset segments, that will be brought about as a result of the COVID-19 pandemic. It discusses sustainable development guidelines and primary trends, which will depend on the pandemic spread and possible mutations from this time forth. The research elaborates the idea of real estate market changes. Historically, worldwide pandemics bring certain changes in the real estate segment. The current pandemic will bring with it the irreversible effect creating a different perception and attitude towards accommodation and commercial property in financial, socio-economic, and environmental terms. Aspects of sustainable construction investment and real estate development in the post-pandemic era, along 
with their trends and interrelations, are presented in Figure 1. These factors are briefly analyzed below.

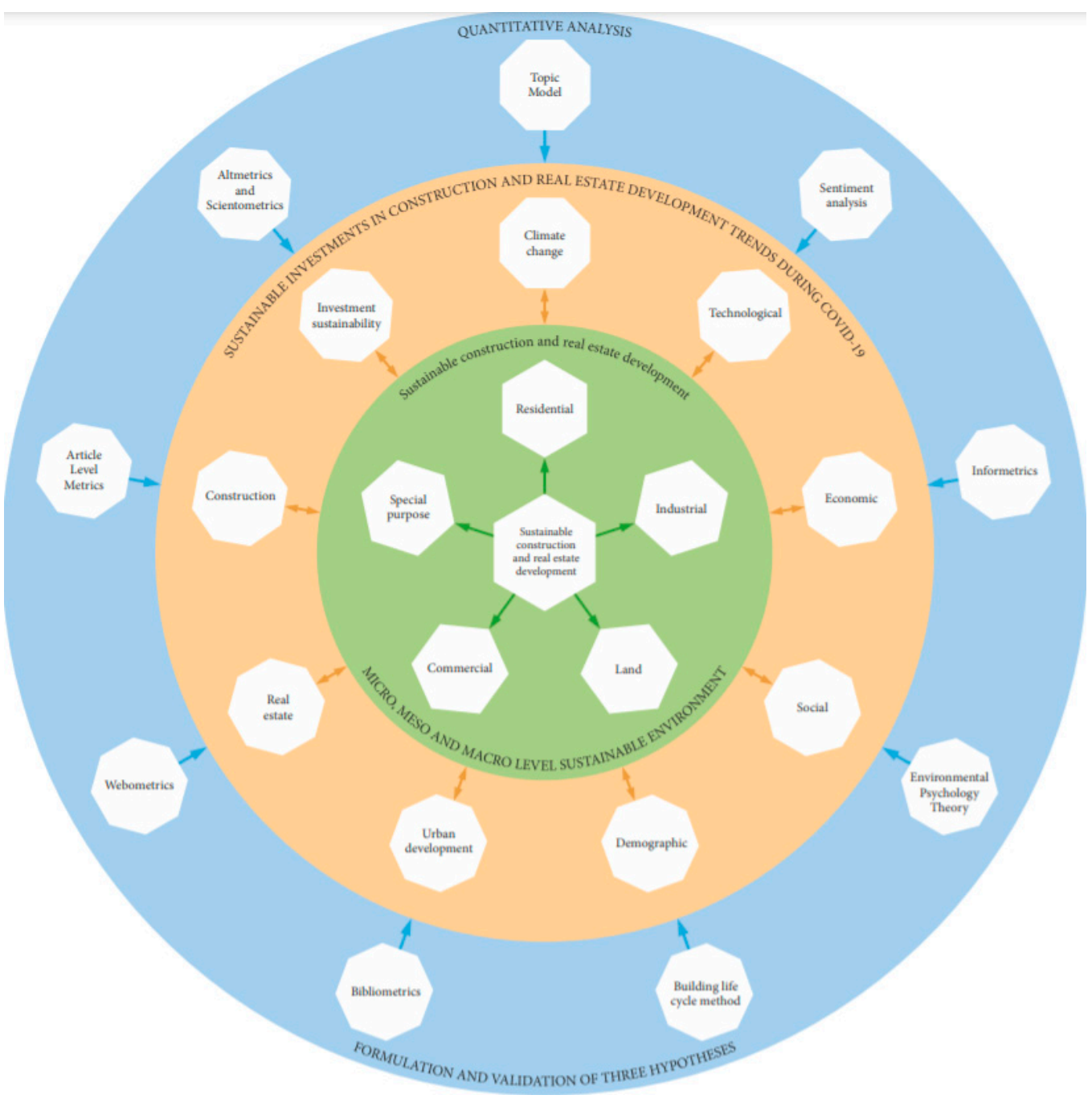

Figure 1. Quantitative and qualitative investigation of sustainable construction investment and real estate development during and after the pandemic along with the formulation and validation of three hypotheses.

Legend:

1. Climate change trends (the new technologies introduced reduce usage of materials, carbon emissions, etc.)

2. Technological trends (digitization, smart amenities, increased use of technology by commercial real estate and accelerated adoption of digitally connected construction)

3. Security trends (stronger cybersecurity measures)

4. Economic trends (low interest rate, businesses faced with inequality, continuing issue of affordable housing, rise of alternative assets, lower demand for commercial office space, intra-regional investment, growing labor needs, rising material costs, and increased infrastructure spending)

5. Social trends (remote worksites with mobile access and utility management for remote work)

6. Demographic trends (continued population declines in major cities)

7. Urban development trends (increased demand for suburban life, household consolidation, and ongoing "smart city" developments) 
8. Real estate trends (increased importance of rental property amenities, increased single-family rentals, focus on residential projects, changes in home ownership and customer-centric real estate)

9. Construction trends (industry adaptability and resilience, increased use of offsite prefabrication, 3-D printing, increased focus on green building, modular and offsite construction, and greater priority for indoor air quality)

10. Investment sustainability trends (environmental, social, and corporate governance (ESG) criteria to generate long-term, competitive, financial returns and positive societal impact)

Figure 1 presents the classification of a full range of real estate types: residential, commercial, agricultural, industrial, and special-purpose properties. The same or similar classifications are mentioned by many practitioners and researchers [12-18]. The classification can also be enhanced by including other aspects various researchers propose.

Wojewnik-Filipkowska et al. [19] note that various classifications of real estate are possible based on different characteristics. Based on structure it can be classified as land, buildings, or infrastructure, based on current usage it can be classified as residential, commercial, or governmental, based on importance in can be classified as either necessary or unnecessary for operations, while based on ownership it can be classified as owned by a school authority, a municipal housing company, municipal utilities, or a treasury department. One of the classifications considers the accessibility of urban facilities and services, which include hospitals, schools, educational centers, shopping centers, and recreational centers. This is a primitive factor, but the collection of available urban facilities can make a neighborhood either more or less attractive to a particular purchaser based on their household needs [20].

Real estate classifications can assist with portfolio selection, asset management, and performance appraisal, and there have been several attempts to find suitable groupings [21]. Traditional real estate classification models, as pointed out by Jackson and White [22], take into account the location and the level of economic activity within the sector relevant to the real estate in question. One classification was proposed by Graham and Bible [23] with age and condition; rental rates and occupancy rates; location; and construction quality as the four factors serving as the basis of their classification. Location, goodwill of the developer, and the quality of construction are the three points that Sehgal et al. [24] suggest should be considered in the selection of real estate assets.

Different real estate websites consider different perspectives when classifying nearby amenities available close to a piece of property. Life, health, catering, transportation, and education are the points considered by gz.fang.com, whereas gz.julive.com looks at hospitals, education, transportation, business, etc. Different approaches to classification of supporting facilities available nearby, however, do not mean classification lacks consistency. An important factor for real estate is convenience, and the classification of supporting facilities available nearby should include as comprehensive details of the daily commuting needs of residents as possible [25]. Kumari and Maan [26] analyzed image and scene (living room, kitchen, bathroom, bedroom, front yard, and backyard) classifications.

If a piece of real property scores high in the market's potential classification system, it attracts institutional and individual investors; when local authorities become more sensitive to the development of the area and the real property market receives a boost, the image of a city, community, or region can improve [27]. Mixed-use real estate, when a piece of property is used for multiple purposes, can also be added to the mix in the classification presented in Figure 1. An example would be both commercial and residential spaces available in the same building.

The proposed methodology (see Chapter 2) fits all possible CIRED classifications.

This study integrates different methods including the building life cycle method, environmental psychology theory, topic model, and some essentials of scientometrics, article level metrics, informetrics, bibliometrics, sentiment analysis, altmetrics, and webometrics. 
Bibliometrics provides the method for analyzing bibliographic data taken from published literary sources, according to Pulsiri and Vatananan-Thesenvitz [28]. Thereby, it becomes possible to review an entire body of knowledge pertinent to a select field of inquiry. Bibliometrics makes it efficient to discover, arrange, and examine massive amounts of historical data, as Daim et al. [29] claim, which, according to them, assists in pinpointing "hidden patterns". Such patterns serve scholars in the process of making decisions. Meanwhile Porter $[30,31]$ and Pilkington $[32,33]$ actually classify materials taken from authors, organizations, countries, collaborations, co-citations, and other similar sources during the process of their studies as being pertinent to how bibliometrics can reveal hidden patterns. A reflection of the study of disciplines and their dynamics appears in the production of their literature. The terms that reference this process in component fields are bibliometrics, scientometrics, and informetrics [34].

There is an informational definition of webometrics that is scientifically related. It incorporates quantitative aspects of construction along with applications of information resources, structures, and technologies, which Thelwall et al. [35] employed in their study. This study appears in the world wide web drawing pertinent to bibliometric and informetric approaches. The actual, original definition of webometrics that predominates in the field was established by Björneborn and Ingwersen [36]. They propose that it is the study of quantitative aspects pertinent to construction as well as the use of information resources, structures, and technologies referenced from the web, drawing on bibliometric and informetric approaches. Another definition was proposed by Thelwall [37] as the study of web-based content with primary quantitative methods. Its goal relates to social science research when employing techniques that are not specific to any one field of research.

No one indicator is able to satisfactorily measure the scientific impact of a multidimensional construct. Nonetheless, PLOS (Public Library of Science) has endeavored to achieve measurement by collecting and displaying a variety of metrics for all its articles since 2009. PLOS employed an array of different, categorized, article-level metrics (ALMs) and, at the same time, provided the same for the community-at-large. PLOS additionally collects different metrics, not only its statistics on the use of citations and usage, which measures the number of views and downloads pertinent to some articles. It also gathers data on the following: How many times has an article been saved in an online reference manager such as Mendeley? How many comments appear in the online discussions segment of an issued article? How many times does an article appear in a science blog or in social media? How often have other scholars recommended an article? Obviously, if only citations are considered, a wealth of this other information would be missed [38]. The three main categories for classifying scientometric indicators are journal indicators (JI), author indices (AI), and article level metrics (ALM). A frequently criticized impact factor is among of the most popular JIs, which additionally contain an article influence score, eigenfactor, and others. The h-index is the simplest and most popular of the AIs. However, AIs may also contain different variants such as the g-index, A-index, R-index, and others. There is a monotonous growth among most of these, named indicators, which do not include ageing. Certain efforts have been made to overcome this issue, such as the AR-index and discounted cumulative impact among other endeavors [39].

The online metrics measuring scholarly impact instead of traditional citations include altmetrics. Although altmetrics are commonly understood, there is no distinct definition of this indicator [40]. Quite a broad definition of altmetrics was proposed by Priem [41], as the study and application of scholarly impact measures based on online activity tools and environments. Meanwhile, the elements of online, scholarly impact traces refer to the altmetrics manifesto Priem et al. [42]. Definitions offered by Weller [43] are worthy of consideration. This scholar proposes that altmetrics include assessment methodologies pertinent to scholarly activities serving as citation-based metric alternatives. Weller [43] additionally proposes that assessment methods stemming from different user activities in social media environments are also altmetrics. However, Priem et al. [42] suggests that 
altmetrics usually describes alternative metrics to the established citation counts and usage statistics and/or metrics about alternative research outputs, not journal articles.

The discipline of scientometrics employs mathematical methods of quantifying the scientific research achieved by respective employees that unearths the scientific development process. Additionally, scientometrics provide a needed scholarly basis for scientific decision making and management [44]. Since scientometrics employs citation analysis and other quantitative methods for assessing scientific research activities, it can actually guide science policies [45].

Conventionally known modeling methods analyze formal texts, including papers, news, and blogs. Furthermore, these presume that topical factors alone generate links. Thereby topic-irrelevant links typically affect the learned topics of these methods on social networks. Artificial priors have recently been discovered to recognize links that the popularity factor in topic modeling generates. Nevertheless, such methods are not able to capture the distinct properties of each link very well by using global priors. Thus, these continue to endure the effects of topic-irrelevant links [46]. Guo et al. [46] proposes overcoming such limitations with a unique social-relational topic model. This model analyzes the topics of relational users for each link, thereby lessening the effect of topicirrelevant links.

An application of social media can be more meaningful when its analysis is taken from the writer's rather than from the reader's perspective in a classical sentiment analysis [47]. The affective topic model that Rao et al. [47] propose stems from their objective to bridge the gap between social media materials and a reader's emotions; therefore, they introduce an intermediate layer. The social emotions of unlabeled documents could be employed for classification purposes as well as for generating a social emotion lexicon by this described model [47].

The research's object consists of sustainable construction investment and real estate development, the contributing to it, and desire to fulfill its stakeholders' aims, COVID19 condition, and external micro-, meso-, and macro- level surroundings as a whole. A sustainable construction investment and real estate development subject model was established in order to achieve a detailed investigation of this object.

The target of investigation is the expansion of sustainable construction investment and real estate development effectiveness by applying a newly developed sustainable construction investment and real estate development topic model.

\section{Methodology}

The available literature on sustainable construction investment and real estate development pertinent to the current COVID-19 pandemic has been reviewed. This review is the topic of the present article. CIRED search keywords, which are later described, were employed for examining the Elsevier Scopus, Google Scholar, and Clarivate Analytics' Web of Science electronic databases along with other reliable and credible informational resources such as the American Society of Civil Engineers. Searches were restricted to studies published inclusively from 1998 up to 2021. A versatile quantitative and qualitative investigation on pre-, intra-, and post-pandemic sustainable construction investment and real estate development (CIRED) was performed by applying the building life cycle method, environmental psychology theory, topic model, and certain essentials of scientometrics, article level metrics, informetrics, bibliometrics, sentiment analysis, altmetrics, and webometrics. The introduction presents a brief description of these methods.

"Post-pandemic" analyzes seem to be quite popular globally. For example, such articles in Web of Science number 1025, in Google Scholar-26,700, and in ScienceDirect31,535 . There are also an ample number of such articles around the world, e.g., in the issues published by the Lancet [48-50], which forecasts trends for the year 2100. Additionally, the research results obtained from quantitative and qualitative analyses show that it is possible to forecast sustainable construction investment and real estate development during the post-pandemic period. 
The intention for the design of the current review was initially to build bridges between academic research policymakers working in the field of sustainable construction investment and real estate development and the society-at-large. However, the COVID-19 pandemic prompted an undertaking to summarize literature available in the aforementioned fields regarding the concerns within these industries relevant to this illness. The composition of the central research enquiry is sustainable construction investment and real estate development, contributions to the same in the endeavor to fulfill the aims of involved stakeholders, the existing COVID-19 condition, and the external micro-, meso- and macrolevel surroundings, all taken as a single entity. The following research questions were raised in an effort to analyze and write-up the CIRED big picture in detail:

Q1: Are the keywords relevant to construction investments and real estate development (CIRED) interrelated?

Q2: Do COVID-19 and pandemic-related national policies affect CIRED and its investors? Do investment strategies affect the spread of COVID-19?

Q3: Does the totality of an integrated analysis of the life cycle of CIRED, its investors, the pandemic context, and the micro-, meso- and macro-environment significantly improve the effectiveness of a CIRED analysis?

The basis for compiling the research hypothesis consists of the raised questions.

As part of this research, dedicated to the study of research literature, and the statistical analysis of relevant articles from a range of bibliographic databases, the CIRED Topic Model was developed in the following seven steps:

1. a search was done;

2. a 3D CIRED map was created;

3. CIRED-related papers printed in 2019-2020 and found by definite search keywords were compared;

4. a 1st Hypothesis on the distribution and correlation of keywords was proposed;

5. a colored document-frequency matrix was created;

6. two more hypotheses (Hypotheses 2 and 3) were proposed, validated, and linked;

7. micro-, meso-, and macro-level CIRED trends were established

Each of the steps is briefly described below.

The first step involved a search for research papers in Web of Science, Google Scholar and Science Direct. A set of keywords was used for database searches and papers were selected based on a range of criteria such as construction investment, real estate development, civil engineering, COVID-19, sustainability, residential, industrial, commercial, land and special purpose real estate, risk, strategies, trends, and others. The scope of our search was limited to studies published in 1998 and later with the day of the search, 1 May 2021, as the end point.

Between 1999 and 2021, for instance, the Web of Science Core Collection database published 11,332 construction investment articles with the following number of papers in different Web of Science Categories: 1446 in civil engineering, 1381 in economics, 1132 in environmental sciences, 953 in construction building technology, 744 in environmental studies, 678 in green sustainable science technology, 543 in business, 541 in business finance, 436 in urban studies, 359 in regional urban planning, etc. The following items were published on CIRED: 6813 articles, 4338 proceedings papers, 255 reviews, etc.

The paper is built on the keywords identified from readily available databases. These keywords from databases under deliberation are analyzed quantitatively (how many articles there are containing the keywords) and qualitatively (the main results obtained are written up in texts). Therefore, we hold the opinion that all the papers within the scope of CIRED research have been analyzed quantitatively and qualitatively by the use of specific keywords.

A 3D map, created as part of Step 2, is presented in Figure 2. The map is based on Elsevier's Science Direct database search results. The figure illustrates the similarities between various topics by showing their distribution over different keywords. All topics are labeled for the additional indication of the best way to record the semantics of the 
top keywords. For example, Figure 2 shows the keywords assume from 2019-2020 search for the following keywords: (a) residential real estate and investment, (b) industrial real estate and investment, (c) land real estate and investment, (d) commercial real estate and investment, and (e) special purpose real estate and investment. The size of each circle in Figure 3 represents the number of 2020 articles published in various Elsevier Science Direct journals based on the mentioned keywords.

(a)

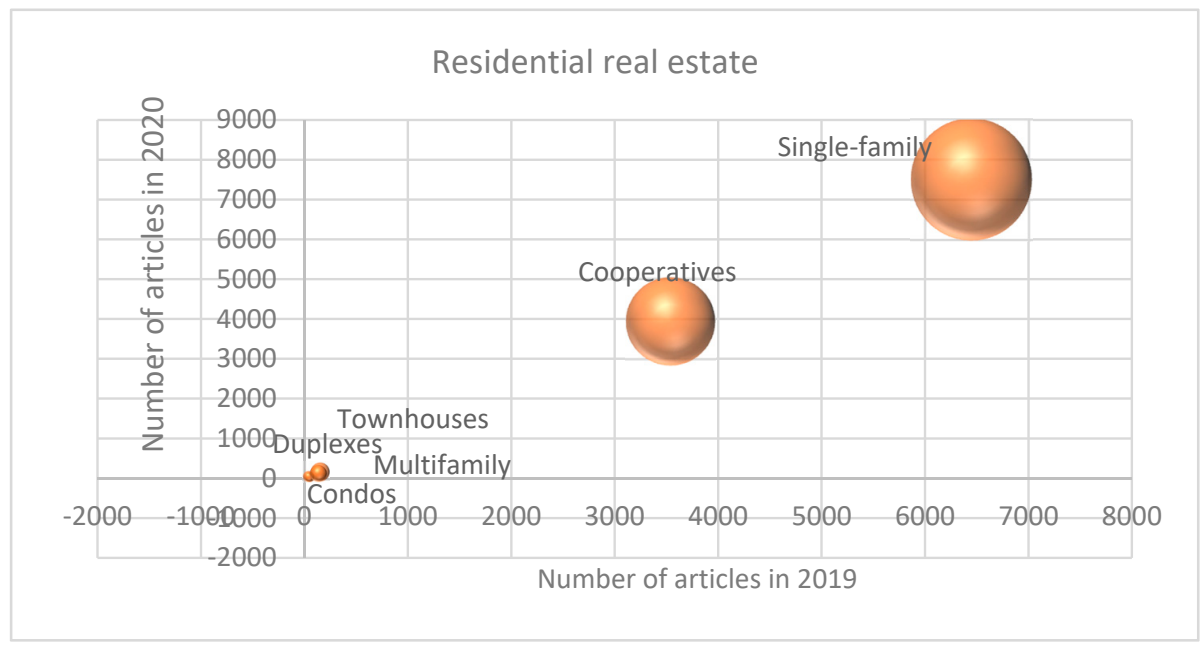

(b)

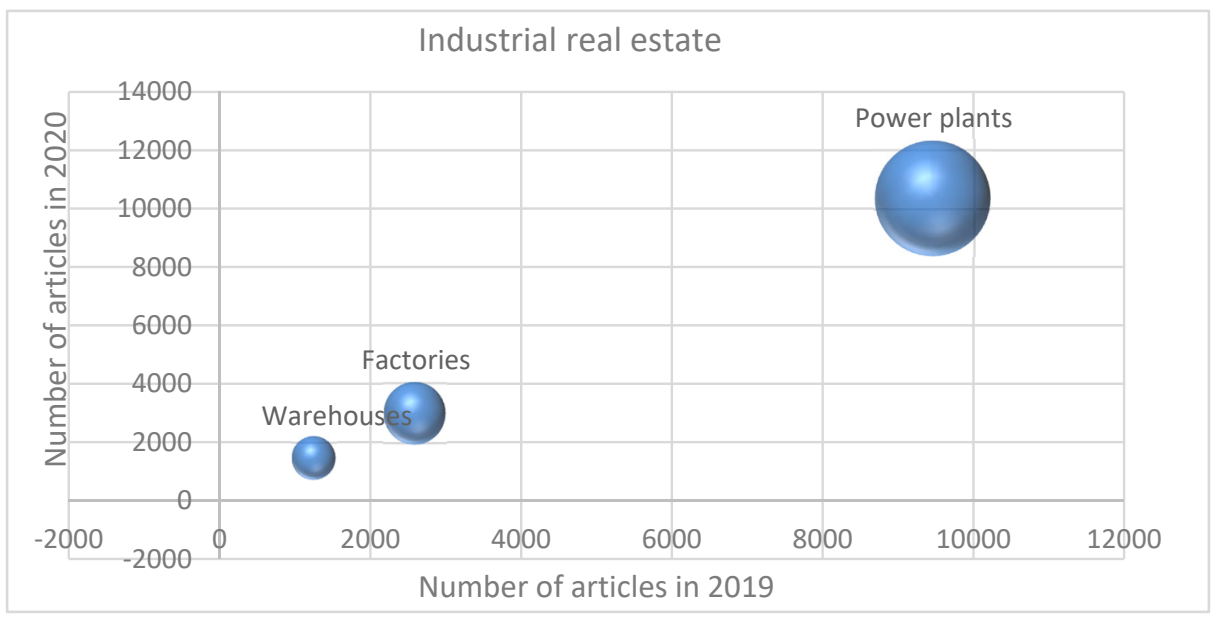

Figure 2. Cont. 
(c)

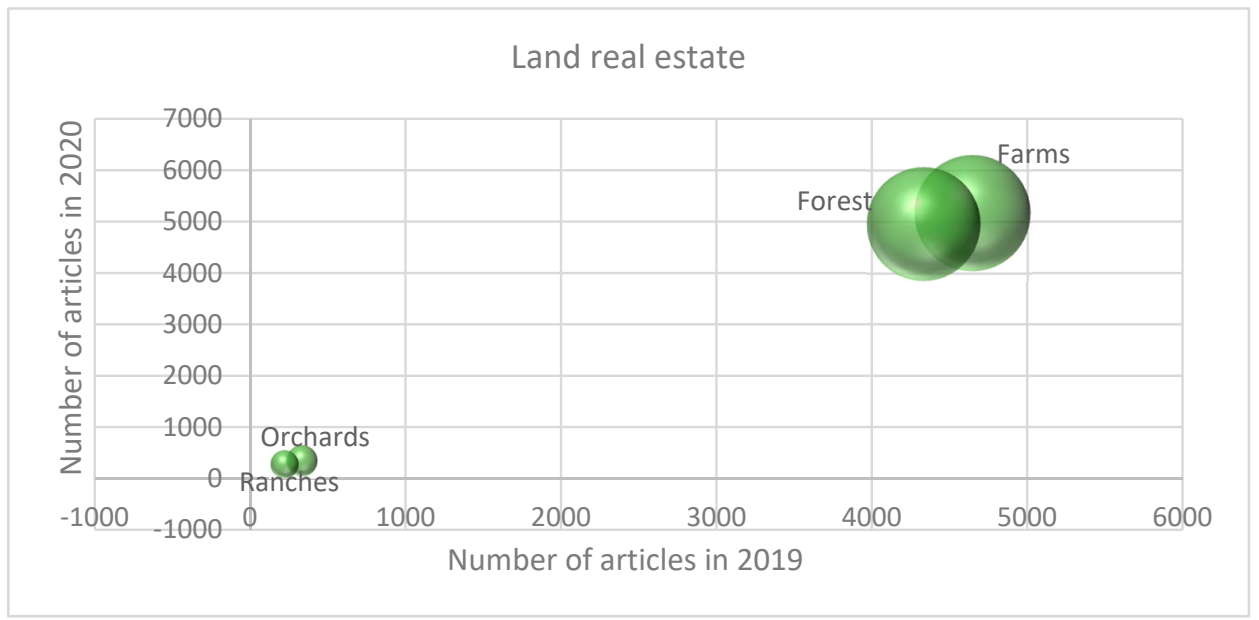

(d)

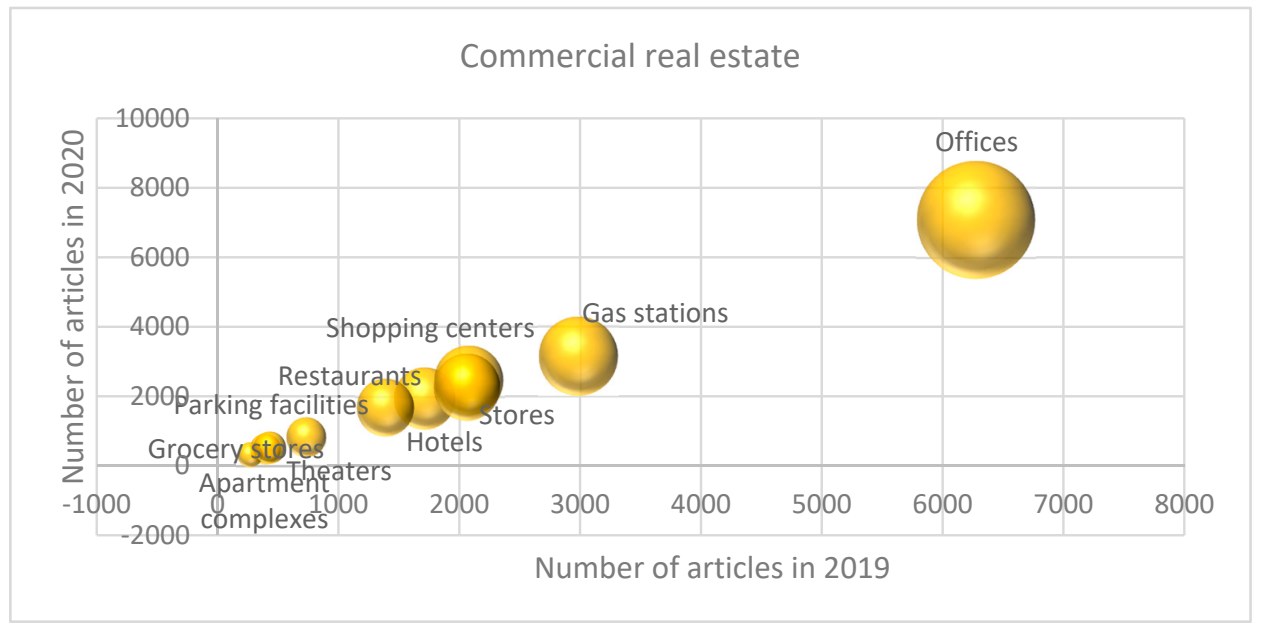

(e)

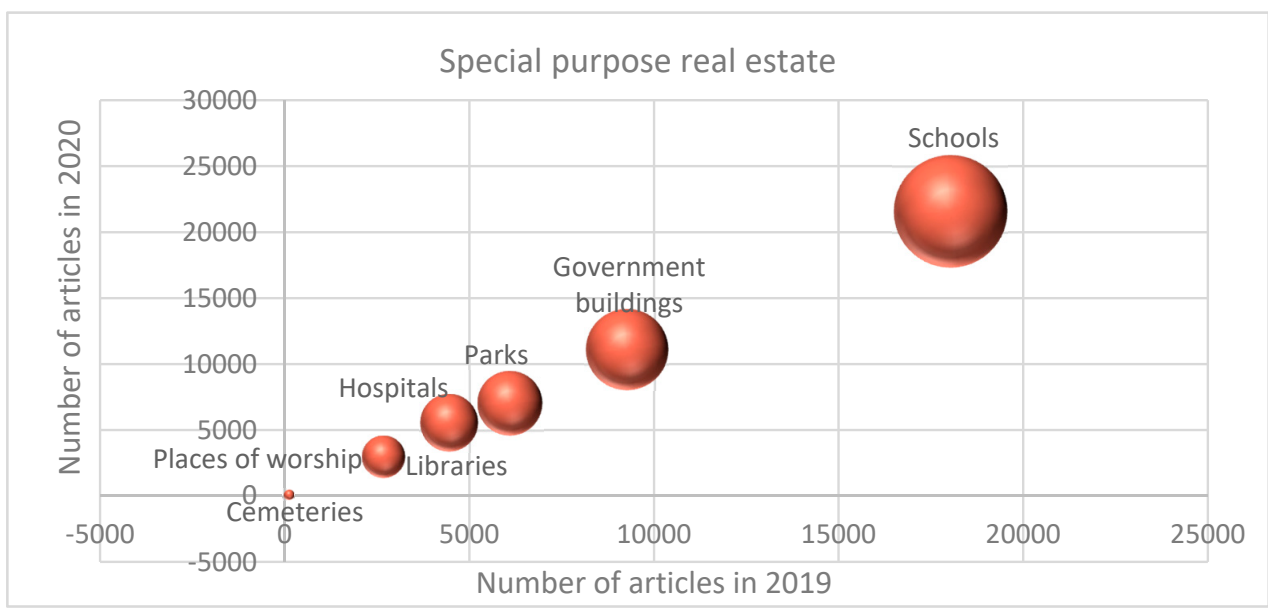

Figure 2. 3D maps with different-sized circles to represent the numbers of 2019-2020 articles published in the Elsevier Science Direct database for the following keywords: (a) residential real estate and investment, (b) industrial real estate and investment, (c) land real estate and investment, (d) commercial real estate and investment, and (e) special purpose real estate and investment. 
(a) Residential real estate

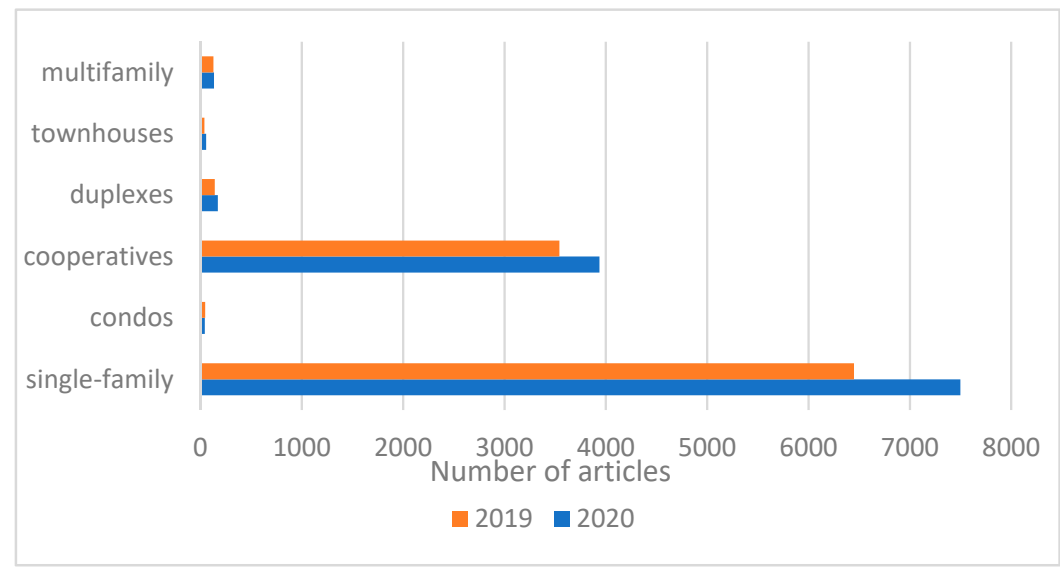

(b) Industrial real estate

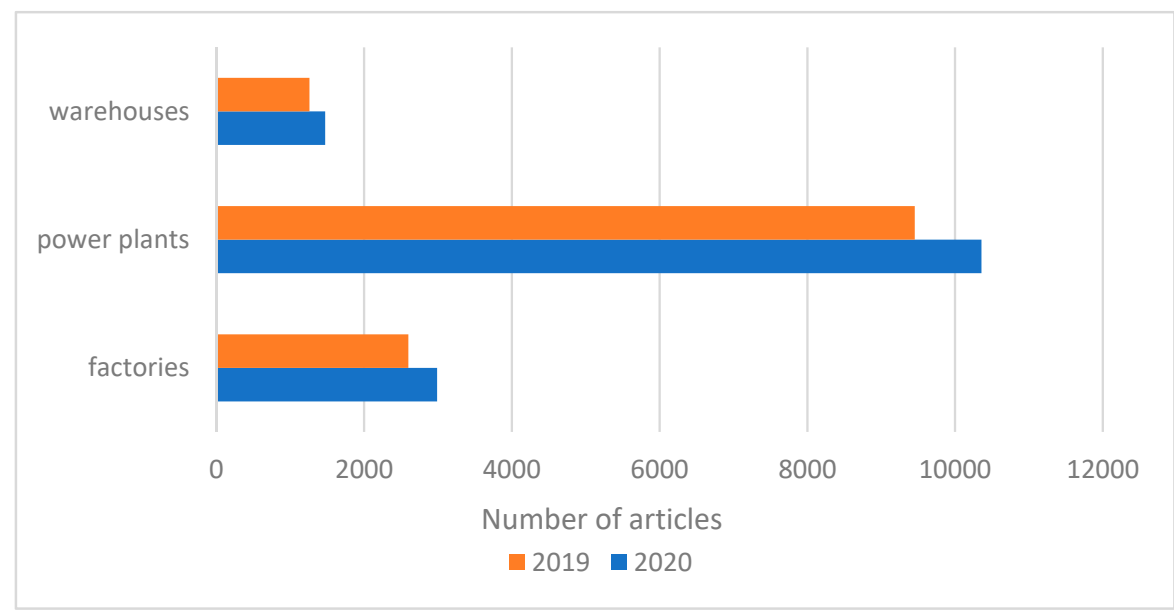

(c) Land real estate

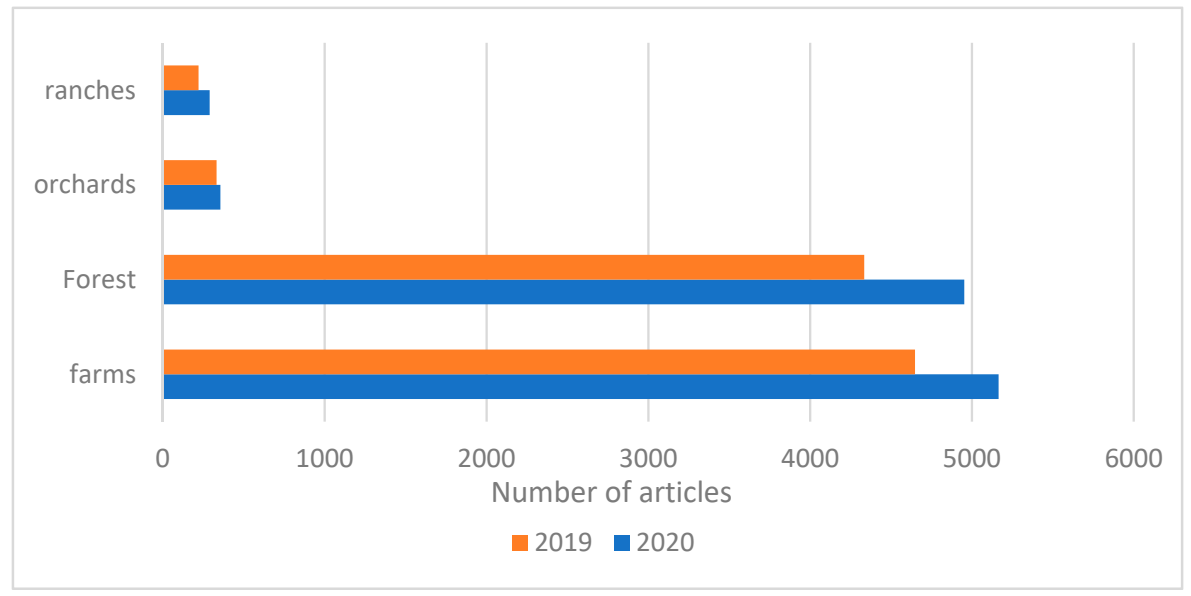

Figure 3. Cont. 
(d) Commercial real estate

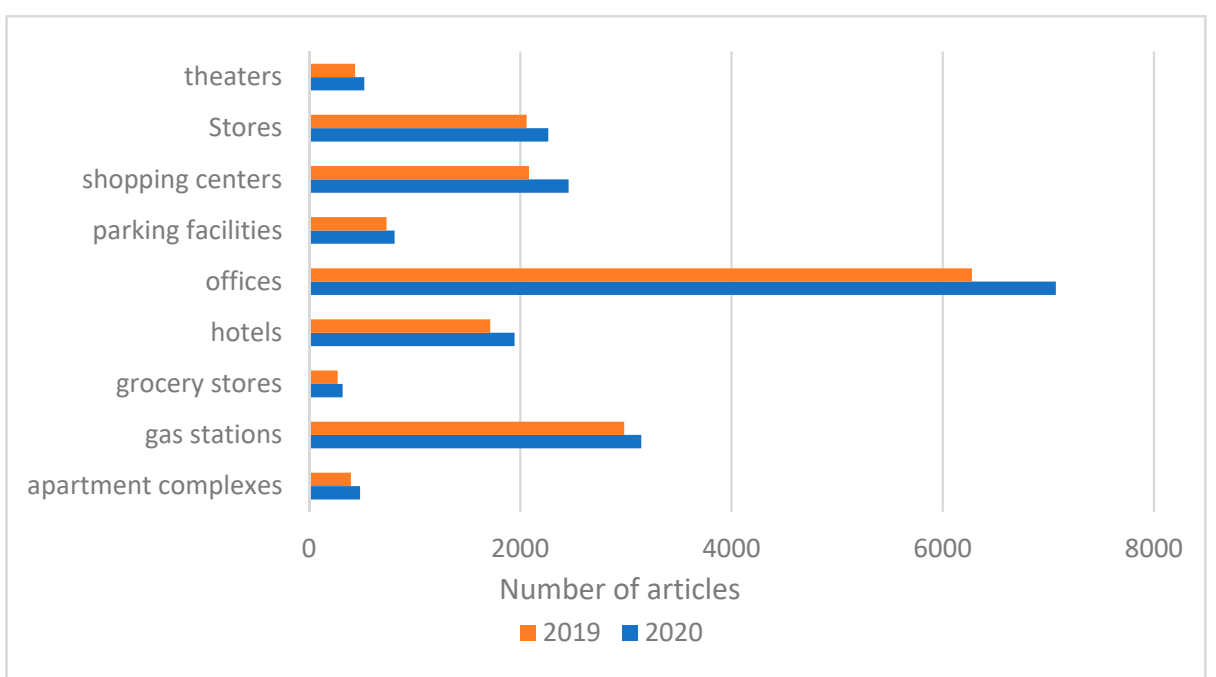

(e) Special purpose real estate

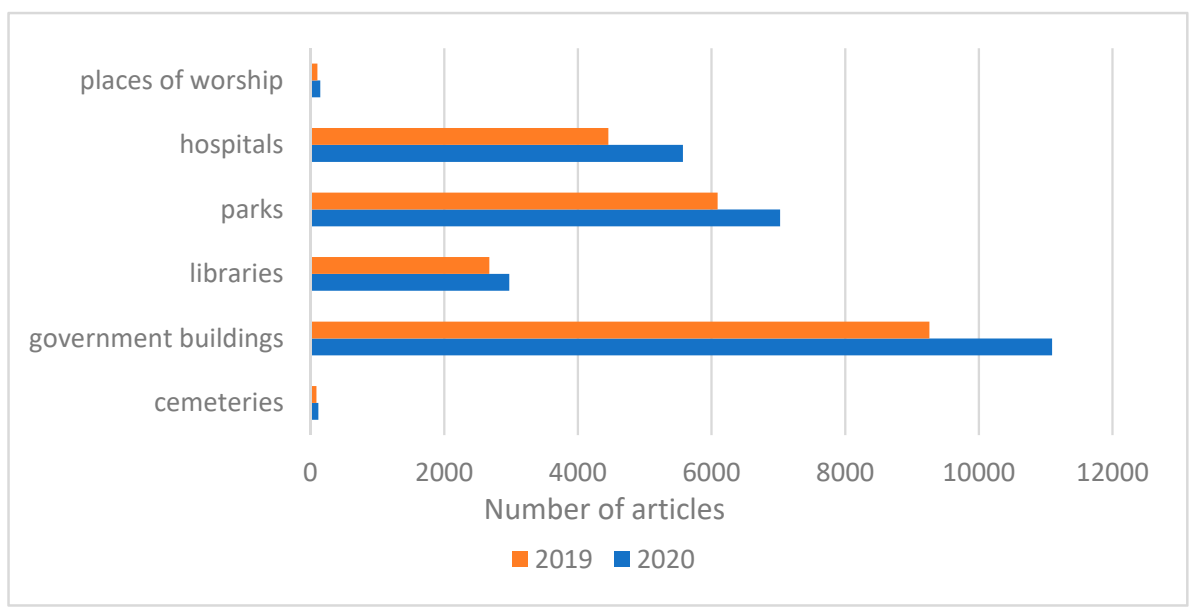

Figure 3. Collation of papers published in 2019-2020 in the Elsevier Science Direct database for the following keywords: (a) residential real estate and investment, (b) industrial real estate and investment, (c) land real estate and investment, (d) commercial real estate and investment, and (e) special purpose real estate and investment.

The compilation of the 3D map is in a three-dimensional sphere. The $X$ axis displays the 2019 results, whereas the $Y$ axis displays the 2020 results. The $Z$ axis, where the number of 2020 searches is suspended, is reflected by the size of the bubble (scope of the search).

Step 3 involved a comparison of papers printed in 2019-2020 in Elsevier Science Direct found for the following keywords: (a) residential real estate and investment, (b) industrial real estate and investment, (c) land real estate and investment, (d) commercial real estate and investment, and (e) special purpose real estate and investment. The total quantity of papers printed in Elsevier Science Direct in 2020 was $15.61 \%$ higher than in 2019 based on the mentioned keywords.

Step 4 involved presenting and validating the distribution and correlation 1 st Hypothesis of keywords. As suggested by investigators working in this area, topic relation meters are a qualitative approach for automatic uncovering of a topic's coherence [51,52]. The underlying idea stems from the linguistics distributional hypothesis [53]. In addition, keywords with comparable meanings have a tendency to appear in almost identical circumstances. Topics are considered coherent any time all or most words are related between themselves [54]. This research also proposed hypothesis 1 (see Table 1): 
Table 1. Strong correlation coefficients gained among residential real estate and commercial real estate.

\begin{tabular}{|c|c|c|c|c|c|c|c|c|c|c|c|c|}
\hline & \multicolumn{2}{|c|}{$\begin{array}{c}\text { Residential Real } \\
\text { Estate }\end{array}$} & \multicolumn{10}{|c|}{ Commercial Real Estate } \\
\hline & $\begin{array}{l}\text { Single- } \\
\text { Family }\end{array}$ & Cooperatives & $\begin{array}{l}\text { Apartment } \\
\text { Complexes }\end{array}$ & $\begin{array}{c}\text { Gas } \\
\text { Stations }\end{array}$ & $\begin{array}{c}\text { Grocery } \\
\text { Stores }\end{array}$ & Hotels & Offices & $\begin{array}{c}\text { Parking } \\
\text { Facilities }\end{array}$ & Restaurants & $\begin{array}{l}\text { Shopping } \\
\text { Centers }\end{array}$ & Stores & Theatres \\
\hline single-family & 1 & 0.998857609 & 0.99388799 & 0.954403551 & 0.954403551 & 0.993192574 & 0.993628616 & 0.97575933 & 0.983551995 & 0.993653389 & 0.994720214 & 0.913005767 \\
\hline cooperatives & & 1 & 0.993160446 & 0.984543879 & 0.960366376 & 0.993459236 & 0.991286491 & 0.978740358 & 0.985521474 & 0.995148577 & 0.996037263 & 0.909229002 \\
\hline $\begin{array}{l}\text { apartment } \\
\text { complexes }\end{array}$ & & & 1 & 0.98971233 & 0.957624301 & 0.984941956 & 0.982602524 & 0.984506485 & 0.978254443 & 0.992578623 & 0.988343034 & 0.881230379 \\
\hline gas stations & & & & 1 & 0.940822182 & 0.967460598 & 0.977432403 & 0.978857917 & 0.964507344 & 0.981760469 & 0.980088551 & 0.840560341 \\
\hline grocery stores & & & & & 1 & 0.963407374 & 0.923667713 & 0.977025896 & 0.981813038 & 0.972979144 & 0.972010935 & 0.854483561 \\
\hline hotels & & & & & & 1 & 0.985424609 & 0.973953815 & 0.987543981 & 0.991298056 & 0.993004255 & 0.928051521 \\
\hline offices & & & & & & & 1 & 0.954977303 & 0.963859502 & 0.980842839 & 0.982675265 & 0.916196969 \\
\hline $\begin{array}{l}\text { parking } \\
\text { facilities }\end{array}$ & & & & & & & & 1 & 0.982824235 & 0.986497721 & 0.979963454 & 0.852731323 \\
\hline restaurants & & & & & & & & & 1 & 0.988855726 & 0.98932029 & 0.89865398 \\
\hline $\begin{array}{l}\text { shopping } \\
\text { centers }\end{array}$ & & & & & & & & & & 1 & 0.994105605 & 0.894033416 \\
\hline $\begin{array}{l}\text { stores } \\
\text { theaters }\end{array}$ & & & & & & & & & & & 1 & $\begin{array}{c}0.905889551 \\
1\end{array}$ \\
\hline
\end{tabular}


Hypothesis 1 (H1). CIRED-related keywords show strong mutual correlations.

The matrix presented in Table 1 shows strong correlations between CIRED-related residential real estate and commercial real estate (Table 1).

The correlation analysis showed that the number of articles found according to the question posed for a search correlated. This indicates that the concepts selected for posing the search question were accurately chosen to reflect the selected subject matter suitably and fully. Furthermore, it can be asserted that the articles are interrelated and reflect associated matters under examination.

Other search terms also show strong correlations, which prove the right search terms were selected for the big picture analysis related to pre-, intra-, and post-pandemic CIRED. This study also confirmed the distributional 1st Hypothesis that the CIRED-related keywords show strong correlations with each other.

Step 5 involved creating a colored document-frequency matrix. Its columns and rows are presented in Table 2. The columns list the keywords for investments in residential real estate and commercial real estate and the rows show the quantity of papers discovered in Science Direct by concrete keywords. In 2020, 2266 articles containing the keywords investment and stores were published in the Science Direct database, and 2060 such articles were published in 2019. Each number is in a color-coded cell of the matrix, where the color represents a certain number of published articles: darker colors indicate higher counts.

Table 2. Keywords for investments in residential real estate and commercial real estate and color-coded cells where the color indicates the number of published articles (darker color means more articles).

\begin{tabular}{|c|c|c|c|c|c|c|c|c|c|c|c|c|c|}
\hline & Res & $\begin{array}{l}\text { dential I } \\
\text { Estate }\end{array}$ & & & & & Cor & nmercial & Real Es & tate & & & \\
\hline હ્خ & 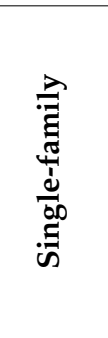 & 总 & $\frac{\mathscr{d}}{\stackrel{x}{0}}$ & 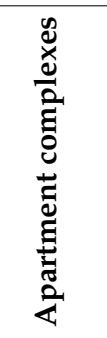 & 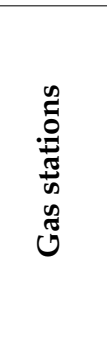 & 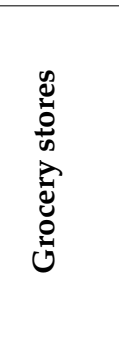 & $\begin{array}{l}\frac{n}{0} \\
\stackrel{0}{0} \\
\end{array}$ & $\stackrel{\mathscr{U}}{\sharp}_{0}^{\infty}$ & 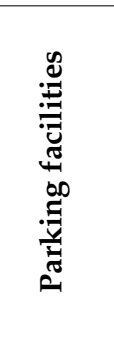 & 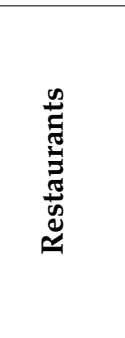 & 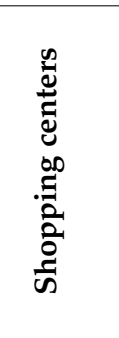 & 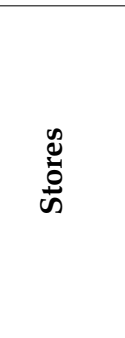 & 总 \\
\hline \multicolumn{14}{|c|}{ Web of Science results: } \\
\hline $\begin{array}{c}\text { Total } \\
\text { Publications }\end{array}$ & 66 & 9 & 1 & 1 & 2 & 2 & 23 & 175 & 3 & 6 & 23 & 19 & - \\
\hline h-index & 18 & 3 & 0 & 0 & 1 & 0 & 5 & 23 & 1 & 1 & 6 & 5 & - \\
\hline $\begin{array}{l}\text { Average citations } \\
\text { per item }\end{array}$ & 17.32 & 8 & 0 & 0 & 0.5 & 0 & 8.39 & 11.8 & 0.67 & 13.5 & 5.13 & 5.05 & - \\
\hline $\begin{array}{l}\text { Sum of Times } \\
\text { Cited }\end{array}$ & 1143 & 72 & 0 & 0 & 1 & 0 & 193 & 2065 & 2 & 81 & 118 & 96 & - \\
\hline Scholar results & 70,100 & 48,100 & 13,600 & 43,600 & 146,00 & 61,100 & 156,00 & 419,00 & 82,500 & 152,000 & 163,000 & 264,000 & 54,200 \\
\hline Wikipedia, mln. & 37.5 & 3.2 & 0.684 & 204 & 33 & 272 & 22.9 & 38.9 & 59.4 & 21.6 & 54.8 & 864 & 42.2 \\
\hline Facebook, mln. & 94.4 & 43.7 & 39.9 & 909 & 183 & 254 & 70.7 & 180 & 159 & 123 & 279 & 1560 & 11.8 \\
\hline Twitter, mln. & 123 & 17.3 & 17.9 & 615 & 99.5 & 140 & 68.6 & 163 & 256 & 129 & 151 & 1330 & 12.2 \\
\hline Scienceblogs & 41,000 & 8 & 24,700 & 8 & 8 & 145,000 & 8 & 22,000 & 23,400 & 67,600 & 27,900 & 108,00 & 52,200 \\
\hline $\begin{array}{c}\text { Positive Google } \\
\text { search results, } \\
\text { mln. }\end{array}$ & 169 & 15.3 & 4.22 & 350 & 84.8 & 55.6 & 20.5 & 337 & 151 & 69.6 & 405 & 348 & 64.9 \\
\hline $\begin{array}{c}\text { Negative Google } \\
\text { search results, } \\
\text { mln. }\end{array}$ & 45.5 & 10.2 & 2.11 & 206 & 71.4 & 34.3 & 16.3 & 324 & 76.7 & 45.3 & 173 & 155 & 52.1 \\
\hline
\end{tabular}


Table 2. Cont

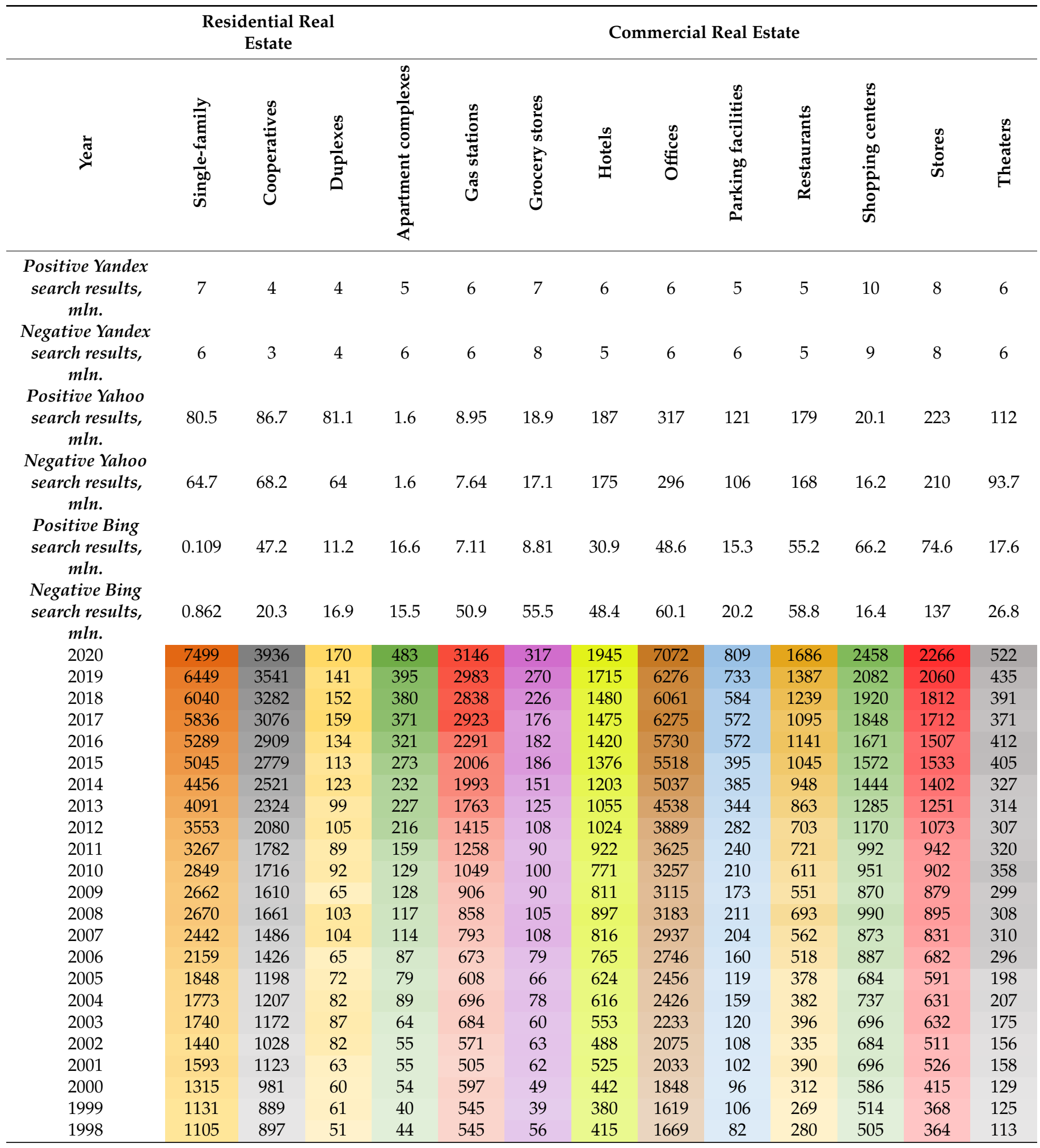

The basis for compiling Table 2 is the number of search results. The keywords entered into the search field are "residential real estate" and "single-family", "residential real estate" and "cooperatives", "residential real estate" and "duplexes", etc. The Web of Science and Scholar databases were employed for the analysis. It was noted, while conducting the Altmetrics analysis, that the number of search results is not submitted when, e.g., directly searching a Facebook or Twitter page. The filtered flow is constantly renewed. Thereby the 
Altmetrics analysis was performed by employing Google's search system by additionally entering the keywords "Facebook", "Twitter", "Wikipedia", and "Scienceblogs". The sentiment analysis was performed by employing different search systems (Google, Yandex, Yahoo, and Bing) and additionally entering "positive" and "negative" keywords.

Upon analyzing the gathered data, it was established that the number of academic articles, according to the selected keywords, increased in all subject areas over the period under analysis. However, the average rates of such an increase varied by different subject areas. The number of articles published in the area of land real estate showed the most rapid increase. The number of articles published in this field annually increased, on average, by 10.1 percent over the period under analysis. The slowest growth was established in the field of commercial real estate. Here, the number of academic articles increased, on average, by 7.6 percent annually. The rapid increase of academic publication in the area of land real estate may be due to the fact that this field had the lowest number of publications initially. Thereby, authors may have wanted to fill the informational gaps in this field.

The analysis of articles in the field of residential real estate revealed that the greatest increase in the number of articles appeared in 2020 as compared to 2019, which arose under the keywords of townhouse ( 28.6 percent) and multifamily ( 24.6 percent). Thus, it can be concluded that there was an increase in the interest of scholars in multi-unit, residential buildings during the pandemic. Upon performing the analysis of articles in the field of industrial real estate, the articles that increased in number the most during 2020 were those associated with warehouses (17.1 percent). Thus, it can be concluded that the authors writing about the topic of real estate development paid the greatest attention to warehouses. This can be explained in the sense that the role of warehouses became more important during the pandemic to ensure the uninterrupted flow of supply chains.

The greatest increase in articles on the subject of land real estate during 2020 were those in which the keyword forest predominated (31.4 percent). The explanation for this is that an interest in environmental protection and sustainable development grew during the pandemic since the stoppage of different manufacturing over the pandemic clearly showed the negative effect of industry on the natural environment.

The analysis of articles pertinent to the subject of commercial real estate revealed that the greatest growth occurred in articles containing the keyword restaurant (21.7 percent). Such an interest could be explained by the fact that the food services industry was one of the most negatively affected branches during the pandemic.

Meanwhile, articles pertinent to the field of special purpose real estate that grew the most over the year were those pertinent to places of worship (40.8 percent). Such growth during the pandemic might be explained by the fact that such places attract many people. Additionally, such places are associated with faith and hope, which are highly meaningful for people. Therefore, such places of mass gatherings during the pandemic meant a great deal to people, and the safety of people had to be assured at these sites.

In summary, it can be asserted that, during the pandemic, the greatest attention of authors writing in the field of construction investments was aimed at assuring the safety of people in construction and at construction sustainability.

Step 6 involved a methodical analysis looking for links between CIRED and COVID-19 to examine the hypothesis regarding the connections among the pandemic, COVID-19 related national investment policies, and the behavior of investors along with their demands for CIRED. Two hypotheses were proposed in Step 6:

Hypothesis 2 (H2). COVID-19 and pandemic-related national policies affect CIRED and the interests of investors; furthermore, investing strategies affect the spread of COVID-19.

Hypothesis 3 (H3). An integrated analysis of the life cycle of CIRED, the investors, the pandemic context and the micro-, meso-, and macro- environment as a whole significantly improves the effectiveness of CIRED analysis. 
To validate each hypothesis, the scientific literature from around the world was analyzed and a statistical examination of relevant papers accessible in the Web of Science, Google Scholar and Science Direct was performed. To achieve superior dependability of the supposed connection among pandemic, national CIRED strategies, and the behavior of investors related to their CIRED demands, the authors of this article introduced improvements to the research design. An investigation of worldwide research (Chapters 3-6) and a statistical analysis (Chapter 2) were carried out to validate the two hypotheses.

There can be quantitative content analysis that focuses on counting and measuring and/or a qualitative content analysis that focuses on interpreting and understanding [55]. Either type of analysis involves the categorization or "coding" of words, themes and/or concepts within texts by researchers who then analyze the results. The quantitative method of content analysis provides an opportunity for an explanation of, e.g., the intensity of the envisioning of certain topics and issues within the selected data resource. The number of articles is counted for each topic, except for the main topics of discovered articles, and/or the compatibility of such articles is analyzed. The result of such an analysis permits us to draw conclusions about the dependability of the supposed interconnections between pandemic and national CIRED strategies and about the behavior of investors relevant to their CIRED demands. Therefore, the analysis presented here is, strictly speaking, an integrated quantitative and qualitative analysis.

Step 7 involved establishing CIRED trends at the micro-, meso-, and macro-level by means of an investigation of research literature (Sections 3-6).

Based on the CIRED Topic Model, data and trends was obtained relevant to the conclusions.

\section{Construction Investments during COVID-19}

On Web of Science (WoS), there has been a growth in the number of publications since 2020 about COVID-19 (more than 54,289 references since 2020: $2020(27,945) ; 2021$ June $(26,320))$.

Smart city means the use of different information technologies or innovative concepts for the connection of city systems and services as well as their integration into the city management and sustainable exploitation process in order to increase the effectiveness of the use of sources, to optimize city management and services as well as to improve the quality of life of the citizens. Due to their role in the sustainable management of the city, travel reduction and information spread, smart city projects were considered an important means of effective pandemic prevention and control by not implementing a strict lockdown policy [56-58]. The use of smart city platforms for wise prevention, epidemic control, information selection, and medicine resource adjustment while implementing the epidemic prevention and control attracted policymakers and researchers' attention [59].

A worldwide outbreak of COVID-19 caused enormous challenges to the governance of cities. It is a big question if smart city projects play an important role in COVID-19 prevention and control process. According to the approved data of COVID-19 cases and smart cities project investments in the cities of China, empirical results reveal that smart city projects essentially decreased the number of confirmed COVID-19 cases. Specifically, with an increased smart city investment of one million yuan per 10,000 people, the number of confirmed COVID-19 cases for 10,000 people decreased to 0.342 . The results of heterogeneity analysis reveal that the influence of smart city projects on COVID-19 spread within cities is stronger than in the introduction stage. Besides, the impact is different in cities with different populations. Yang and Chong (2021) in their research provide quantitative proof of smart city projects' influence on COVID-19 prevention and control [59].

COVID-19 convulsions and the unprecedented financial outcomes caused huge uncertainty to future climate actions. Garel and Petit-Romec [60] analyze the cross-section of shares returns during COVID-19 convulsion in order to investigate the approach of the investors and their expectations on environment protection. The results reveal that companies that have responsible strategies in place regarding environmental protection experience better stock returns. This impact is mostly dependent on the initiatives intended 
to fight climate change (e.g., pollutant emission reduction and energy consumption), which are more notable in companies predominantly managed by long-term investors, which has not been noticed until the COVID-19 crisis. In general, the results reveal that the COVID-19 convulsions did not distract the attention of investors away from environmental protection issues. On the contrary, they encouraged them to take even more the responsibility for the climate [60].

Fourth industrial revolution (4IR) technologies appeared to be successful platforms, intended for communication and visualization of construction projects through team meetings. These methods can improve the monitoring of COVID-19 rules on websites. A detailed analysis has been carried out on the extent to which Nigerian construction contractors use 4IR technologies. Thus, this document deals with collective insight about the contribution made by COVID-19 to construction company problems related to the lockdown rules and the role of $4 \mathrm{IR}$ technologies. By considering the non-analyzed nature of the problem, a qualitative analysis method of virtual personal type was used. Twelve semi-structured interviews were made from the selected construction companies and expert consultants who summarized the data by using a topical method. The interviewed participants represented construction companies (six experts were from large construction firms and four from medium construction firms), one expert represented a mechanical engineering company, and one expert worked as a software consultant. The work experiences of the experts in their fields ranged from 15 to 35 years. The interviewed experts were CEOs, project and operation managers, a site safety officer, safety coordinating officer, chief maintenance engineer, and a software expert in construction equipment. The briefing was provided in the invitation letter for the interview. Letters of invitation were sent to intended participants, and 12 virtual interviews took place from late September 2020 to early November 2020. The face-to-face virtual interviews via video conferencing lasted between 45 and $60 \mathrm{~min}$. Collated data were analyzed using thematic analysis. The conclusions divide 4IR technologies into a smart construction site, imitation and modeling, digitization, and virtualization in the context of Nigeria, and most 4IR technologies can be useful in improving COVID-19 compliance. Unwillingness to implement, high implementation costs, inadequate management know-how, resistance to changes, etc. were revealed as the factors preventing the use of 4IR technologies. Conclusions will strengthen and provide a rich understanding of the impact of COVID-19 on construction sites and will help to notify the main interested parties in order to develop a favorable environment for 4IR technology implementation on site [61].

Barlas et al. [62] analyzed big data and investment in Turkey and extended the results to Spain, Mexico, and Colombia. The results of the survey for Turkey showed, that:

- The first important highlight is that the negative effects on investment caused by the COVID-19 shock have been neither as homogeneous nor as permanent as the 2018 financial shock, neither in sectorial data nor in geographical terms. The key reason for this is that machinery investment response has been more differentiated and dispersed and construction was not experiencing a previous boom this time.

- The response of construction investment has been more homogeneous, and it is also recovering faster so far than during the 2018 financial crisis shock. Facing a more negative situation prior to COVID-19 (as the construction industry was experiencing some de-leveraging consequences of the previous financial crisis), the initial response was homogeneous and amplified the already weak situation [62].

\subsection{Property Types within Real Estate}

Property kinds and property classes are identified in real estate. These two terms are different and should be approached as such. A real estate class indicates investment real estate characteristics and is often classified as Class A, B, or C. These classifications were developed by real estate investors, lenders, and brokers to provide the possibility of communicating and assessing the asset promptly. Any guidelines define these ratings and certain controversies may occur regarding the concrete asset. 
On the other hand, the real estate class is classified into two main kinds of assets: commercial and residential. Residential real estate is considered real estate intended just for sustainable living. It involves one-family accommodation, townhouses, blocks of flats, and holiday houses. Residential real estate is regarded as an investment provided that the estate is not occupied by the owner and is owned for profit-through rent or its value increase.

Commercial real estate, or CRE, includes any asset that generates income. Types of commercial real estate include blocks of flats, retail, office, self-service warehouses, hotels, mobile houses, land, industrial, production, warehousing and delivery, and flexible space [63].

COVID-19 has had a different impact on the worldwide commercial real estate industry according to the jurisdiction or asset class. NEW JERSEY-7 October 2020-The Dodge Momentum Index increased by 3.7\% to $130.8(2000=100)$ in September, compared to 126.2 in August. The Momentum Index, issued by Dodge Data and Analytics, is a measure of the first (or primary) report related to nonresidential building projects assessed once a month that determines nonresidential buildings' construction expenses during the entire year. Both components of the Momentum Index increased over the course of a month. The commercial component increased by $3.9 \%$, while the institutional component increased by $3.2 \%[64]$.

COVID-19 is not considered an existential threat to real estate. Real estate is mostly space where people stay. We need space for our work. In addition, at our core we are social beings. Thus, the need for real estate has not changed. The place of events has changed. People are working from home recently and tend to shop more online. However, people still need sustainable physical space. This requires flexibility. This does not show a reduction in demand [65].

Retail and office space did not prosper before the pandemic, and the situation got even worse during it. Certainly accommodation is not in demand, and apartments and student accommodation are in a bad situation. These are not just segments-the place of real estate is also important now [65].

Before the pandemic, about three-quarters of US retail areas had become unnecessary because of e-commerce and rebuilding. Lockdowns highlight that, and the shake phenomenon in retail will remain. However, retail that will continue will be incredibly efficient because the physically built retail will only supplement e-commerce and gain business advantages through multi-channel retail trade [65].

Moreover, investors should not treat all retail premises in the same way. The sale of food products is increasing, thus, shopping centers that are dependent on food shops are doing well. Closed shopping centers that hardly survived had already been on the way of reorganization - into concentrated mixed-used towns or otherwise. Essentially, some (but not all) shopping centers are not located in perfect places, thus, they have come to the point of reorganization into different purpose buildings. Simon Property Group, the leading owner of shopping centers in the US, had a conversation with Amazon about a conversion of department store areas into distribution centers. Shopping centers usually have perfect access to highways and are located in the vicinity of residential centers [65].

We will see tenants making long-term investments since people now acknowledge that COVID-19 is not going to be the last pandemic. Investors will jump to high-quality and sustainable real estate, and we see signs of that already. In order to control investment risk, think not only about the differences between real estate segments but observe entities or assets in a sector. You need long-term lessees who will stay for a long time. You need a good sustainable building in a good place in order for you to replace the lessee in case he leaves. You also have to find entities that do not need refinancing (expiring debt, or real estate may be used during a recession) [65]. 


\subsection{Property Types within Real Estate}

COVID-19 focused our minds on the purpose of the office and to which extent it should be important in the policies and budgets development process of the company, besides, it highlights too clearly the strengths and limitations of home.

COVID-19 actually showed that a large part of work that is usually performed in the offices may indeed be performed outside them. Some realized that they can work more efficiently from home and are better able to enjoy their free time. Very few miss their morning traffic.

However, besides speeding up the work from home tendency, COVID-19 has also revealed its limitations-in know-how economics, the success of the organization will still depend on face-to-face interaction, cooperation, and coincidence. With common flexible work, the office may become a vital anchor. The office undoubtedly plays an even more important role in providing learning opportunities for younger staff. Exchanging work practices is not the only decisive factor. The International Monetary Fund has described the 'Great Lockdown' as the worst economic recession since the Great Depression in 1930 and predicts a setback at least as bad or even worse than the worldwide financial crisis of 2007-2008 [66].

The demand of occupiers will inevitably decrease, although this will differ in variant segments. The most aggrieved tourism and leisure industry will require less common space, while some professional services companies may go on operating with changed working practices. Rapidly growing segments, i.e., technology and electronic commerce, are already more geared towards virtual operation-according to Jack Dorsey, CEO of Twitter, employees can constantly work remotely if they want to [66].

Organizations have already begun reducing spaces so that each employee had less than one desk, and the recession is likely to accelerate this tendency. According to Magnusas [42], during the crisis, efforts are always made to reduce fixed costs, i.e., offices. A typical lessee will start thinking that probably they do not need any space for $100 \%$ of their employees, but only $75 \%$ or $60 \%$. On the other hand, they might remain operating in the same area during and after the crisis [66].

COVID-19 is a bizarre phenomenon because of its sudden influence resulting in a push from organizations in the opposite direction-needing more space for one employee. Companies have been pressing more and more people onto the floor for a long time, and as little as $8 \mathrm{~m}^{2}$ per employee had become a typical density prior to the pandemic. For offices to reopen safely and maintain physical distance, the proportion of employees per square meter or floor space will have to increase again, with changes to start times and continued remote working likely to take place [66].

It is difficult to say now whether we will ever feel comfortable again occupying space so close to others, thus, it is very hard to predict the long-term influence that physical distancing may have on office requirements. Perhaps a better question is whether organizations will want the same amount of space that they had occupied before. Now companies will know that they can operate with less office space. However, they will also find that they need better and more resistant office space [66].

What about the new office changes? Is additional space indeed necessary? This will condition supply and demand dynamics in local markets. In some areas, structural undersupply of modern, high-quality office space has already been experienced, and COVID-19 is likely to strengthen this, even if general demand remains the same. Changes may also take some time. As 'CBRE Canada' emphasized, commercial real estate is an outdated industry - two years have passed since the level of free offices reached the highest point after the worldwide financial crisis [66].

Since the revolution of working from home, which was caused by COVID-19 pandemic, will likely continue, investors are concerned about the lack of future sustainable office space demand and many are now thinking about alternative uses. Buildings suitable for alteration provide investors with more flexibility during the COVID-19 pandemic. This flexibility is very important when considering the increasing concerns surrounding the 
viability and profitability of office spaces, as well as other investments in real estate, in an environment where a large number of employees work from home and many will not return to their pre-COVID-19 work routines after the lockdown restrictions are lifted.

A study performed by 'O2 Business' in collaboration with 'ICM' and 'YouGov' reveals that " $45 \%$ of the labor force in the UK consider that flexible work will constantly increase, and $33 \%$ predict that time of working from home will increase to at least three days a week". The increase in remote working will reduce the demand for office buildings, risking resulting in an increased number of vacancies [67].

\section{Real Estate Investment during COVID-19}

Ref. [68] analyzed the impact of COVID-19 on the American economy from the perspective of job losses. By using a statistical method referred to as topic modeling and detailed datasets received from the Worker Adjustment and Retraining Notification (WARN) Act and a depository of seven million companies, the authors revealed essential conclusions about the most aggrieved US states and work segments. Since Arkansas, Colorado, Connecticut, Georgia, Kentucky, North Carolina, and Virginia indicate significant noncompliance with job loss models between the periods before and during the COVID19 pandemic, the target number of jobs were lost in the recreational and philanthropic segments. Recently, the most aggrieved segments have planned longer lockdown periods or prepared for having fewer consumers instead of reopening [68].

A few observations noted during this research stood out. First of all, it is very important to understand that economic situations will change significantly due to the presence of COVID, i.e., some industries will be shocked, while others will be stimulated. Secondly, our conclusions reveal that some industries can actually remain buoyant as a result of the interaction of several social and economic factors. For example, contrary to expectations, aviation and retail (scoring $S=0.77$ and 0.85 , respectively) indicate fewer job losses during COVID-19. Thirdly, our study on job loss datasets reveals that people working in higher salary (suggesting elevated) positions have incurred a more negative impact than their colleagues on a lower salary. This could be the case because some jobs that come with a lower salary, such as working in food stores, maintenance, food preparation, security, etc., must remain functional during lockdowns. This research could widely influence public policymaking to strengthen economics and governmental subsidization of particular segments [68].

Ref. [69] suggested the study of real estate investment trust (REIT) funds' operational results before and during the COVID-19 pandemic in 2020 and chose a safety-first portfolio selection methodology in identifying an optimal portfolio for investment between behavior levels (fearful-neutral-hopeful). The selection model was applied to the last 500 historical trade days and was used as a return scenario. The data check also covers the previous 100 days before and during the COVID-19 pandemic, and two standard markets were used (SPX and XLRE). The results of the research suggest that the US REIT investment fund is a better investment than XLRE, since it overtook the market during COVID-19 when investors stayed neutral. As a result of this research, scientists think that the conclusions can help investors to begin rethinking US REIT in their investment policies [69].

This study suggests a comparison of possible behavior return of each investor from fearful (P-0), neutral (P-0.5), and hopeful (P-1) by using a SF model before and after COVID19. Market portfolios for testing by using the safety-first model are designated as P-0, $\mathrm{P}-0.5$, and P-1 with hope being 1 and fear being $0 . \omega=\{0,0.5,1\}$ where $\omega$ is any number $\mathrm{i}$ from 0 to 1 . As i approaches 1 , an investor is more optimistic and hopeful. US REIT was selected as an investment fund, and two markets (SPX and XLRE) as the standard. Scenarios were estimated by considering 500 historical trade days, when the same returns were distributed. At the end of testing, the research revealed that the return on investments can differ depending on the behavior of the investor in the market and the selected standard indicative market. Furthermore, the pandemic had an impact on the results of testing. The REIT investment fund research result helps us to identify a good return possibility 
for investors during COVID-19, provided they are not neutral to return and risk. The researchers provide us with a case study on investments in REIT, and upcoming research may involve studying and determining the factors as to why REIT investment is a good investment regardless of the COVID-19 pandemic. Moreover, upcoming research may choose to test different standards in order to compare and analyze the results [69].

The influence of the COVID-19 pandemic on retail real estate and high streets was assessed in [70]. Although some variations induced by urbanization and digitalization have occurred over the last several decades, it seems that the COVID-19 pandemic accelerated these processes. We studied strategic events data on chosen UK retailers and insights of interviews with the retail asset managers and tenants of retail real estate business development and high streets in the UK. The conclusions revealed many tendencies, and some aspects stood out, e.g., distance from non-core assets, greater significance of asset choice, reconsidering of physical store function, ESG factors in asset and investment control, as well as clients involving a crucial factor for landlord selection. Our conclusions also emphasize different impacts on high street and urban retail. The work deals with emphasizes the prompt need to change the location of physical stores and involve digital platforms as principal functions of multichannel retail trade businesses. With more proof manifesting in the world after COVID-19, the upcoming studies should be concentrated on a more detailed consideration of the outcomes at the company and local level, as specified in this work.

Having considered the increased fluctuation and uncertainty in financial markets as a result of the COVID-19 pandemic in March 2020, we notice that retail investors reduced instant trade and increased contrary trade activity in the primary phase of this crisis [71]. We also notice that the influence of Robinhood investors on some market quality measures depended on the market conditions, suggesting better market quality during less tense periods and lower market quality in the course of the first weeks of the pandemic in the US.

It is anticipated that planning and construction decisions, as well as methods of investment, will vary after the pandemic [72]. It is anticipated that new attitudes to the economics of solidarity and space in city territories will be developed and new professions and business fields will soon develop. Accommodation markets will be stable, however, variations in commercial real estate markets will speed up. Most people will ambiguously distribute their capital to new long-term investments and will choose deposits, foreign exchange, gold, and other related securities investments and will be able to take up shortterm investments. As a result, investments and manufacturing will reduce, growth will diminish, and an increase in employment will become impossible. Real estate and property owners and users may see changes in credit use, rents, and agreements [72].

People and real estate businesses should be prepared for upcoming disturbances by innovative technologies [72]. It is estimated that there will be an increase in smart buildings and technologies, which maintain less contact with buildings and structures. The number of shops in cities is decreasing, storage spaces in the city are increasing, and e-commerce marketing is quickly growing. With a decrease in administrative spaces in public and private institutions and office demand, home offices or flexible working hours may result in reducing companies' use of technology and employment. The digitalization of business and home life has become inevitable. New regulations will make all segments, especially banks, insurance companies, private pension systems, and other institutions structurize the real estate and asset management field [72].

The Italian real estate segment is experiencing an unprecedented situation that may have dramatic outcomes [73]. The extreme COVID-19 situation emphasized that household spaces are outdated in terms of their functionality, especially now that people are having to work from home and minors are having to isolate at home as a result of uncontrollable health risks. The residential and unlimited real estate markets, which used to be individual, are today intervened in. Thus, it seems that new market sectors may be identified and analyzed according to their key components and features. 


\subsection{Real Estate Operation}

Official statistics from China show that housing prices grew dramatically between 2007 and 2014, but more moderately in recent years. According to the National Bureau of Statistics, China's total real estate investment was 0.36 trillion yuan in 1998 and increased to 10.98 trillion yuan by 2017, an almost 30-fold increase within 20 years. Existing data (from the China Wealth Management Product Market Development and Evaluation) shows that nearly $25 \%$ of trust funds flow to real estate, and housing price fluctuations lead to the conversion of properties from real asset attributes to financial attributes [74]. Real estate also accounts for a major part of financial assets within Chinese nonfinancial firms. Since the late 2000s, the government has increasingly shifted its focus to financial stability and the imbalances between finance and the economy. Under the central government's guidance, regulators have sought to stabilize housing prices through restrictions and limiting investments in real estate financial assets [74].

A successful investor takes up all possible actions to get a decent return. Investors make financial decisions based on the risk and return of various assets, however, other factors influencing investment benefits are investment goals, time perspective, safety of the main entity, future security, market environment, and heuristics [75]. Market environment is an important portfolio distribution factor; thus, a question arises regarding how the pandemic has influenced the decisions regarding portfolio distribution. The AHP results reveal that the preference for risky assets was higher than that for risk-free assets before the spread of COVID-19. Shares are a highly desirable form of investment. Since the COVID-19 pandemic, however, what counts as a desirable investment has changed. Risk-free assets are gaining more value. Insurance is the most desirable investment possibility, followed by gold, bank deposits, and public provident funds (PPF) [75].

Cities are constantly changing in terms of their physical and demographic qualities, as well as their social and spatial distribution [76]. For example, in the current COVID-19 pandemic, cities face many challenges such as constant abrupt tourism extinction (which can be a driver for gentrification and a significant part of the local economy) or the voluntary movement of richer people to their second homes in less populated areas, in addition to enhanced uncertainty about what will happen to cities in near future [76].

Ref. [77] analyzes the effects of the COVID-19 pandemic on commercial real estate prices. They report that retail and hospitality properties, and to a lesser extent office buildings, have been affected the most by COVID-19. The other sectors, in particular the residential and industrial sectors, have shown more resilience. Overall, prospects are significantly better for industrial and residential real estate and to a lesser extent offices than for retail and hotel properties. Prices are likely to depend more heavily and more narrowly on the type and location of the assets, while current and future rental conditions should be taken into account to a greater extent in the risk premium [77].

According to a financial representative in Vietnam [78], as a result of the COVID-19 era, the real estate markets predict fewer revenues in the upcoming years. For example, REC-12 (Alavo Nghia) expects its income to amount to 166 billion VND, reduced by 24 percent compared to 2019, and the revenues before taxes amounted to 93 billion VND, reduced by 19 percent year-on-year. While struggling with this worldwide pandemic, most leading real estate investors in Vietnam have considered the integration of more 4.0 technologies in order to gain an apparent competitive advantage. Model results suggest that it is poised to have a huge impact on the real estate industry in Vietnam for the assessment of their past, present, and future comparative analysis with other competitors, especially during the COVID-19 pandemic, since it appeared that the pandemic had an essential impact on this industry. The authors hope that the results will reflect the present state of the real estate industry from the aspect of technical and technological effectiveness. Thus, the insights of this document could help managers, investors, and policymakers to upgrade their decision-making process and settle the main operation indicators in order to improve real estate for sustainable development [78]. 


\subsection{Accommodation Prices}

Although worldwide asset markets faced unprecedented risk and uncertainty as a result of the COVID-19 disease convulsion, the real estate market in most cities in the world proved to be secure regarding negative impact. Ref. [79] is the first effort to determine the impact of the pandemic on accommodation prices by applying a price gradient analysis to the COVID-19 epicenter in China. According to microlevel accommodation transaction data in 62 areas from nine districts in Wuhan City from January 2019 to July 2020, the hedonic pricing and the price gradient models reveal that soon after the pandemic convulsion, accommodation prices fell by $4.8 \%$ and $5.0-7.0 \%$ during one year, respectively. Although the accommodation prices raised after the lockdown period, gradient models reveal that the price gradients equalized from the epicenter to the urban periphery. The price rises also significantly reduced after the city went into lockdown in highly populated areas [79].

Since the real estate industry plays an important role in the economy of the country, public authorities should focus more on the impact of COVID-19 on accommodation prices and implement a complementary real estate policy [80]. By using data about the confirmed community-level COVID-19 cases in a month and the accommodation price in China, we can analyze the impact of COVID-19 on the accommodation price. The results reveal that in communities with confirmed COVID-19 cases, there is a $2.47 \%$ fall in accommodation price, and the negative effect can continue for three months, with the scope of the effect actually increasing with time. The effect of COVID-19 on the accommodation price manifests only in the regions with higher COVID-19 infection levels or high mortality rates [80].

\subsection{Accommodation}

During lockdowns, homes became a living and working space as well as an area in which to spend our free time [81]. Thus, homes were modified to meet the new requirements of communities that had to spend a larger part of their day at home. Soon, this will have an impact on the real estate market with respect to tendencies and features of desirable homes.

The performed analysis emphasizes the structural changes of residential asset demand in the Naples city area because of new requirements as a result of COVID-19. Today, cities face crises due to COVID-19, and this means that their spatial organization in particular is not suitable for bringing about the changes caused by COVID-19. The new identity of the post-pandemic city today reflects the long-desired transition aimed at for sustainability at different levels (energy, environment, and society). The performed analysis emphasizes certain structural changes demanded in the Naples city area because of new requirements as a result of COVID-19 and reveals that changes in decision-making regarding the planning and construction of the settlements and investment methods are long-awaited.

Considering that the built environment is responsible for 39\% of global carbon emissions, this situation could be used to tackle climate change, incentivizing and adopting renewal solutions from a greener perspective. In order to strengthen the contribution that the real estate market can make to the fight against climate change, it would be necessary to make the rules on sustainability in construction and the environment clearer and more feasible. This would strengthen the commitment of governments to this goal and increase their financial investment. Researching possible changes and opportunities following the pandemic, this study suggests that a change is expected in decision making about the planning and construction of settlements and investment approaches.

A UK study has shown how COVID-19 has led to changes in housing demands. For example, the increased prevalence of smart working has led to a growing focus on comfort and quality of the indoor environment. Better thermal insulation, acoustic insulation, visual comfort, indoor air quality, and the use of natural light are some of the factors identified by the aforementioned study as buyers' desires for improvement. These elements will lead to greater investments in measures to improve house performance, such as increased thermal or acoustic insulation (which, in turn, would lead to a reduction in $\mathrm{CO} 2$ emissions) [82]. 


\subsection{Health Care}

The COVID-19 pandemic has highlighted nursing home safety and infection control as critical public health issues [83]. The recent COVID-19 pandemic has substantially accelerated the attention towards health-centric topics globally in all industries, increasing the salience and relevance of healthy building in the real estate industry [84]. The shared understanding of a healthy building lies in its human-centered metrics.

With the change in the social and physical environment of socioeconomically and racially separated districts, these districts face a higher risk of gentrification and its effect on health equity (including fear, worry, stress, lack of sleep, worse nutritional habits, lower social cohesion, obesity, cardiovascular diseases or mental health problems, which, for example, all affect different groups of people more intensely) [76]. The intensity of the relationship with these health consequences and the significance of other potential methods, as well as their effect on health, will mostly depend on gentrification factors in a particular district or city.

Gentrification is affecting worldwide neighborhoods more and more. Hence, in order to come to a full understanding of the effect of gentrification on public health, it is very important to find out how different groups of people and kinds of gentrification, e.g., retail, ecologic/environment protection, climate, tourism, students, teaching, or health care, can have a distinct impact on health. However, the development of suitable measures, definitions, and measurements as well as access to data at a suitable geographic scope are still methodological challenges faced in the gentrification and health studies before they can be transformed into policy.

\subsection{Offices}

The discussion about the future of the office has taken on its own life since the implementation of lockdowns. The vitality and utility of the large-scale work at home/remotely/ anywhere experiment has provided challenges and possibilities. To the extent that a traditional ecosystem of commercial property investment is a challenge, the vitality of traditional offices from the perspective of the suppliers and users, and even the future of city centers, have been assessed [85]. COVID-19 pointed to the human element regarding how and where work is carried out by considering the growth of the importance of the health and welfare of the employees and community. It also emphasized the work-fromhome versus living-at-work discussions. Many different participants with much experience and expertise in different aspects of established technological and workplace landscape solving, including health, welfare, anthropological, behavioral change, and sustainability factors, have participated in this paper. This wide scope holistic approach is the basis for the awareness increase, system models, and method proposals for achieving progress in the common real estate (CRE) space.

\section{The Impact of the COVID-19 Pandemic on the Real Estate Industry}

Public opinion shows that COVID-19 has had a significant impact on both accommodation and residential and commercial real estate industries. It seems that understanding restrictions on free movement imposed by governments will produce different insights into the importance of real estate for life and work [86]. Billio and Varotto [86] propose that the lower sustainability of the lease may change the sector of commercial real estate. However, the main change expected is related to the types and standards of buildings.

In this case, a comparison of stock market sector indexes is one of the ways to assess the potential impact of the pandemic on the financial sector [87]. Francke and Korevaar [88] suggest that the pandemic temporarily increased the risk of housing due to rising uncertainty and economic disruption. The authors assert that boosting prices are no longer significantly different from the average trend expected approximately one or two years after the end of the pandemic. The lack of any long-term impact on lease and housing prices is linked with city resilience to major shocks [88]. 
Although there is widespread talk about the negative socioeconomic impact of the pandemic around the world, still, a reluctance to look at the potential positive developments in the real estate market while facing one of the most acute diseases worldwide is displayed. Francke and Korevaar [88] clearly describe the example of Paris, where the pandemic proved to be a catalyst for significant urban change and housing prices recovered even in the most troublesome areas.

\subsection{Guidelines for Real Estate Following the COVID-19 Pandemic}

The case of the Chinese real estate market, considered to be the focal point of the pandemic, demonstrates [89] that a decline in real estate value caused by the COVID19 pandemic was to a greater extent influenced by social constraints and governmental anti-viral interventions to control the pandemic. Jovanović-Milenković et al. [90] agree that owing to threats to the life of the population and restrictions on free movement, the declining demand for real estate might be primarily affected by the population's desire to meet existential needs and maintain personal health [90]. Nicola et al. [91] find real estate uncertainty due to the COVID-19 pandemic to be another reason. Considering the measures of social isolation at the individual level, buyers and sellers are forced to rethink part of the sales process. As a result of insufficient data, the number of studies conducted is limited, however, both a study on housing prices in Italy [73] and the scientific literature suggest that the emergence of the pandemic did not bring about a fall in prices in the real estate area [91,92]. Billio and Varotto [86] prove that the major change in real estate relates to building types and standards.

Cities have historically been a major source of growth, development, and knowledge transfer. Gupta et al. [93] propose this long-term trend has changed as a consequence of the COVID-19 pandemic, which has prompted many residents to seek safer housing near urban centers. Most researchers consider how the COVID-19 pandemic could change the choice of households and residential areas. Due to mobility constraints, many urban residents living in urban centers lack a private yard, and the residents of remote suburbs, particularly those at risk, may feel isolated [94]. Gupta et al. [93] followed the example of the US from December 2019 to December 2020, when the prices of housing far from urban center areas rose faster than those in city centers. Thus, rental prices in suburban areas grew much faster than in urban center during the abovementioned period [93]. A study performed by the national association of real estate agents Realtor concludes that residents preferred real estate with a private yard when purchasing residential housing [90]. Billio and Varotto [86] maintain that families having children will mainly look for independent real estate units such as detached and semi-detached houses with gardens and terraces, and households hoping to work from home may be encouraged to buy real estate outside the urban center where prices per square meter are usually lower, because, as stated by Belk [95], the need to live close to the urban center is reduced. Hence, the perception of the importance of free movement forms a priority for the acquisition of real estate in the suburbs near the biggest cities.

Scientists underline that the COVID-19 pandemic necessitates the redevelopment of existing residential buildings and construction of new buildings [92] that also meet sustainability requirements. A study conducted by Del Giudice et al. [73] also concludes and emphasizes that household spaces are functionally obsolete. Billio and Varotto [86] agree that spaces such as apartment entrances can be converted into a 'decontamination room'. In addition, D'alessandro et al. [96] point out that the transmission of the virus in the household is due to the inadequate housing construction and lack of necessary equipment. The researcher sets out recommendations for safe, healthy, and sustainable housing considering the newly designed and already available housing, including designing green spaces, the adaptability of premises, simple resizing of spaces, redesigning the principles of thermal comfort and indoor air quality, water and wastewater treatment, municipal waste management, the automation of building functions, and selecting appropriate building materials [96]. 
Apart from a significant impact on real estate prices, the pandemic will bring a different understanding of upcoming research on the real estate market, property search, and sales processes [90]. The author notes that the situation observed in the market has stimulated vendors to increasingly use remote communication tools such as virtual communication and 3D viewing, employing Skype or FaceTime to reduce the risk of infection spread [91,92]. Cheng et al. [89] state that the revolutionary platform Haofang XianShangGou, used during the time of social constraints, assisted customers by creating conditions for purchasing houses with reference to $360^{\circ}$ photos, a personal viewing service that blocked purchasing actions performed by other consumers having selected a specific property to inspect, and even paying the deposit. Cheng et al. [89] propose that buying online in the real estate market is revolutionary. Over 8000 transactions were handled within five days of launching the Leju platform. Jovanović-Milenković et al. [90] emphasizes that some world banks started implementing real estate assessments based on virtual tours and approaches.

Fernandes [97] maintains that the pandemic has hit the hotel sector first. Short-term lease online platforms such as Airbnb will hardly reach pre-COVID-19 levels anytime soon $[95,98]$. The hotel sector has been adversely affected by cancellations, traveler distrust of security, and the introduction of social exclusion rules. Billio and Varotto [86] prove that the impact of the pandemic on the segment of this particular type of real estate will remain, as most companies have switched to online meetings, and the impact on the hotel sector will vary from country to country depending on the duration and severity of local travel restrictions and quarantine rules.

Although, as stated by Barua [99], the COVID-19 pandemic has had a significant impact on the real estate industry, recovery is subject to regional economic resilience, business types, and asset class. The authors of scientific literature agree that not all real estate has been treated equally during the pandemic $[77,100,101]$. It seems the assets that suffered most point to the areas of the highest density of people, and therefore we can expect most changes in this particular segment of assets. Billio and Varotto [86] remark that the majority of companies were more likely to use smart work solutions during the pandemic. Meanwhile, property owners and managers consider long-term solutions that will bring changes to commercial buildings to reduce the risk of forthcoming pandemics and thus bring them closer to the requirements of sustainable buildings. Researchers believe that considered changes may affect HVAC standards and the amount of enclosed space per person per square meter $[86,101,102]$.

Tanrivermiş [72] makes the case that the Turkish real estate market shows that following the pandemic the offices of large cities will need to be redesigned, thus substantially changing the use of office premises. The demand for smaller and home offices is expected to rise with the increasing use of virtual offices [72]. The author concludes that the application of different types of technologies in both business and residential segments will be inevitable. In that context, shops will be replaced with storage space, e-commerce will grow, and office space will shrink. The pandemic changes an employee's awareness of workplaces in the case that job specificity is not related to the workplace. The introduced restrictions on movement and social distance requirements forcing people to work from home may significantly change the demand for office space [77], because a large proportion of those working from home are likely to survive the crisis even after the pandemic. Restrictions on free movement, according to Carson et al. [94], have forced less technology-oriented sectors to relocate their activities to the internet, thus reducing the need for offices. As long as social distancing measures, which can be quite protracted, are necessary in the workplace, the space required per employee will increase significantly. This may lead to unexpected, significant changes in the demand for commercial real estate, but overall, a significant decrease in space is reasonably expected [94]. While looking for cost-effectiveness in creating workplaces, Billio and Varotto [86] accept that it would be much easier to create workplaces in the suburbs near residential areas where employees live. This would be much more cost-effective than investing money in the development of proprietary lease real estate. 


\subsection{Real Estate Prices Change Guidelines}

A study by Oyedeji [103], following the example of Lagos, Nigeria, concludes that the COVID-19 pandemic affects real estate supply, demand, and sale and rental values. The majority of the surveyed respondents found the level of real estate transactions to be stable during the pandemic compared to the transactions handled prior to the pandemic. However, the level of supply and demand for industrial facilities (warehouses) increased during the COVID-19 pandemic. Oyedeji [103] and Apergis [104] propose that banking seems to be one of the prevailing problems in real estate transactions.

Considering the example of the Czech Republic, the conclusions of the real estate market analysis provided by Hromada [105] demonstrate that the real estate market frequently encounters delay. Immediately after the measures taken in the country to halt the spread of the pandemic in March 2020, the real estate market stagnated. Starting in June 2020, the market turnover of apartments for sale in the largest Czech cities increased and prices continued to rise. Hromada [105] states that the current prices are higher in and around Prague than those before the outbreak of the pandemic.

A further growth in the prices of apartments for sale is expected in the upcoming period. Hromada [105] identifies the following factors as determining price growth [105]:

- The central bank policy is a quantitative stimulus causing people to protect their capital for fear of inflation thus preventing from a drop in real estate prices even in the case of recession.

- A decrease in mortgage interest rates, lack of alternative investments to capital gains, and a failure in pension reforms.

- Builders seek to sell their products to foundations and corporations thus leaving $20-30 \%$ of the supply of apartments in the sales market. Therefore, the supply of apartments to the general public will be reduced. The missing or urgently required products are expensive.

- A shortage of foreign labor in the construction industry is observed, and the situation will hardly change. On the condition that foreign staff are replaced with local employees, the work done will become more expensive, and the price for the results of this work will increase.

- The aftereffects of the pandemic have hindered ongoing construction and delayed the process of issuing building permits. Hence, the output of new construction will rise more slowly.

\section{Global Construction and Real Estate Markets by Countries and New Shapes} Focusing on Technology, Smart and Green Infrastructure Initiatives

\subsection{Global Construction and Real Estate Markets by Countries}

At the start of 2021, global CRE market acquisitions fell again, marking the fourth quarter of pandemic-related declines in a row. A drop of $24 \%$ year-over-year was recorded in sales across the major income-producing property types, such as apartment, industrial, and office properties. The decline in deal volume, down $12 \%$, was the lowest in the Asia Pacific region, explained by the fact the region had been the first to be hit by the coronavirus pandemic. The declines, around 25\%, are sharper in Europe and North America. In 2021 Q1, only the apartment sector recorded an increase. All other property types experienced declines, with retail and office properties reporting the biggest ones [106].

The commercial real estate (CRE) sector was hit hard by the coronavirus crisis. As countries scrambled to contain the virus and economic activity was severely restricted, global commercial property transactions and prices fell in 2020. The hotel, office, and retail segments suffered a heavy blow and some of the effects could be permanent, as people who moved to online work may continue this practice in the future and other activities may move away from large cities [107]. Fendoglu et al. [107] believe that:

- The CRE sector suffered a heavy blow from the novel coronavirus crisis and possible structural shifts in demand add more uncertainty to the outlook for some of its segments. Enhanced supervisory attention is, therefore, warranted. 
- Misaligned commercial real estate prices, especially with other vulnerabilities present, make the risk of lower future growth higher due to the likelihood of marked price corrections. Such corrections could hurt corporate investment and threaten financial stability. In this scenario, economic recovery would be hindered.

- Near-term policy support to stimulate aggregate demand and ensure the nonfinancial corporate sector access to loans will contribute positively to the recovery in the CRE sector.

- In the case of persisting large price misalignments, policymakers should move quickly to contain vulnerabilities in the sector with targeted macroprudential measures when required. Specific circumstances may also justify capital flow management measures to limit excessive cross-border inflows and the related potential risks.

The global COVID-19 pandemic has dealt a heavy blow to the manufacturing sector, forcing it to consider a sustainable long-term business plan ensuring economic, social, and environmental sustainability. An unprecedented need for higher value by the customer with fewer resources demands these considerations. To ensure long-term business sustainability, innovative integrated manufacturing practices, such as agile manufacturing and lean six sigma, are required. Simultaneously ensured waste elimination and adjusted dynamic changes in the requirements and demands, without compromising the quality, can help with achieving this goal [108].

Despite the serious pandemic-related slumps, the economic situation in the German construction industry is not wholly bad: investment in renovation of residential buildings and new construction is still rather strong and acts as a major boost to the sector. Commercial and public construction is, however, a different story, with many firms dealing with considerable drops in construction investment due to the pandemic. Uncertainty, a distortion of equity, and losses have led to reduced economic activity and additional production capacities are, thus, not required. Online businesses have prevailed over stationary retail. This may also lead to medium-term shifts in demand. However, it is still early to make predictions as to whether this change will last and to what extent it will reach [109].

Social distancing has been pushing more consumers to use e-commerce, and warehouses have become commercial property in high demand. In 2020, investors flocked to industrial properties, and, for the first time, the spending on American warehouses overtook that on office buildings. The market now shows signs of overheating. The coronavirus hit retail properties and hotels very hard, and offices also suffered because of the recommendations to work remotely whenever possible. Warehouses, however, are seen as more resilient property in a pandemic world. As money is pouring in, prices are rising: Real Capital Analytics Inc. reports that, in the 12 months through October, the prices of industrial properties increased $8.5 \%$. Meanwhile, the prices of retail real estate dropped $5.2 \%$ and those of offices remained mostly unchanged. Seen as an alternative to lower-yielding bonds and volatile stocks, real estate has become a popular investment target, and this year investments in industrial and warehouse properties accounted for $20 \%$ of global commercial real estate spending, compared with only 12\% in 2015 [110].

US warehouses, self-storage, and technology were the best performing property types. As many people are working from home, the demand is high for high-tech facilities that host cloud servers and cell towers that transmit data. Retail real estate investment trusts (REITs) and hospitality showed poor performance. The likely cause are the combined effects of imposed lockdowns, cancelled travel, and stay-at-home orders in most locations. Underperformance was also noted in diversified REITs, because many hold multipurpose and retail properties. A drop in demand also affected owners of specialty REITs (e.g., agriculture, golf courses, casinos, and timber). Over the same period, residential and office properties were spared some of the negative effects and a possible explanation is relatively inelastic demand and longer-term leases [111].

Real estate and mortgage markets have been defined by Brodeur et al. [112] as a complex net of interconnected participants such as investors, developers, households, banks, and many others. The market is also characterized by links to financial markets and 
the overall macroeconomy. The COVID-19 pandemic has severely hit real estate markets. We can see its effects in empty shopping malls, abandoned flats in metropolitan areas, and vacant office buildings [100].

The currently available valuations data released by NCREIF and MSCI for Canada, Ireland, the UK, and the US show overall single-digit falls for office capital values in 2020. The falls for retail values were larger, in the double-digit region, whereas industrial capital reported single-digit increases in value. Different regions experienced different levels of real estate investment activity in the second half of 2020. After a sharp fall at the start of the pandemic, transaction activity is already showing signs of recovery in the Americas and Asia Pacific but remains weak in EMEA. In 2020, global investment activity totaled $\$ 726 \mathrm{bn}, 28 \%$ below the 2019 level. The last quarter of the year, as investors completed deals before year-end, saw all regions experiencing the usual seasonal pick-up in activity despite the ongoing pandemic. The sector differences observed in private real estate markets continue to be reflected in the listed market. The listed market data of FTSE EPRA NAREIT show that, in USD terms, global industrial prices by the end of January were $14 \%$ above the end-2019 levels, while offices were down $20 \%$, residential $5 \%$, and retail $27 \%$. Less variation was observed at the country level, with falls of around $15 \%$ in the markets of Japan, Switzerland, the US, and Europe excluding the UK [113].

The real estate and mortgage market is connected to other credit markets, financial markets, and the macroeconomy by potential valuation and wealth effects. The negative effects are expected to lead to more vacant commercial real estate. Accompanied by increased uncertainty, these expectations of low growth lead to a drop in the value of commercial property portfolios held by private and public real estate investment trusts or developers, private equity funds, and high net worth individuals. This, in turn, leads to increased leverage ratios and a demand for higher risk premiums in future investments. Dropping property values make it harder for commercial investors to secure loans. The effect is exacerbated by dropping stock prices of listed real estate companies, which dries up funding liquidity further. Firms with less cash, more debt, and limited profits before 2020 show especially low stock prices during the coronavirus pandemic. Real estate securities are also among the lot $[100,114]$.

With the COVID-19 pandemic continuing for four months already, the hotel and retail segments of the American commercial real estate market show signs of distress. The Q2 hotel deal volume, which dropped to $\$ 642.9 \mathrm{~m}$, or $91 \%$ year over year, is the lowest Q2 volume in RCA history. During the same period, hotel asset refinancing was down about $50 \%$, compared with the same period of the previous year, and about 30\% lower than in the previous quarter. According to RCA, the hotel sector has suffered a heavy blow: the Q2 total inflow of distress was more than three times higher than the average quarterly inflows of 2009. The second quarter saw a surge in reports of potentially distressed assets (the total for the first half of 2020 is $\$ 2 \mathrm{bn}$ ), and the number is expected to rise. Distress sales for hotel assets are higher than any other class of assets, according to RCA. In all Q2 hotel sales, the share of hotels being acquired out of distress was 4\%. RCA said that "if the sector continues to see growing levels of forced sales, it may exit the 'shock and triage' phase of the downturn and head to the 'price discovery' phase at a faster pace than other asset classes." Like hotels, the retail sector also suffered a blow and its Q2 transaction volume plunged to $\$ 4.6 \mathrm{bn}$, or $73 \%$ year over year-a worse Q2 performance has never been recorded for the sector. The total Q2 inflow of distress was more than two times higher than the average quarterly inflows of 2009. The "pain does not appear to be ending" for the sector, according to RCA. A growing flow of reports of potentially distressed retail assets in Q2 led to a total of $\$ 29.4 \mathrm{bn}$ for the first half of 2020 [115].

US commercial real estate suffered a heavy blow from the pandemic, and the market was basically frozen for months: in the first three quarters, total transaction spending dropped more than $40 \%$ compared with the previous year. Hotels suffered the highest drop of $71 \%$, followed by offices with a drop of $44 \%$. The situation of industrial properties, in this context, looked somewhat better, their sales sliding down $25 \%$. In terms of real estate 
spending among American investors, the first three quarters of this year saw the share going to industrial and logistics spaces at $24 \%$, compared with $23 \%$ for office spaces, and for the first time investors spent more on warehouses than on offices. In view of a marked shift towards e-commerce, Jones Lang LaSalle Inc. forecast the demand for new industrial spaces will reach 1 bn square feet by 2025 . A construction boom that concerns some lenders is, therefore, to be expected [110].

The capital value for industrial assets was resilient in 2020 and can be expected to show an upward trend between 2021 and 2025. The situation of the COVID-19 pandemic is different from that of the 2009 financial crisis, when the UK experienced a sharp drop in prices ( $-41 \%$ between July 2007 and July 2009). People have been forced by the pandemic to spend more time at home and their wellbeing there, therefore, now plays a more significant role. This means households may now value properties more for certain characteristics (size and number of rooms, nearby services and retail, location, sunshine, and others) and even be ready to spend more of their budget on the home. These patterns will contribute to higher prices [77].

The new measures of suspended activities make no direct impact on German construction investments and the general environment that has a large amount of pent-up purchasing power, high demand for residential real estate, and low interest rates remains extremely stimulating, especially for residential investment. Beginning in 2021, the deterioration of public finances due to the pandemic will put a certain damper on public investment [116].

China experienced adverse effects with a $30.3 \%$ drop in fixed asset investment and a $16.3 \%$ drop in the real estate development within just the first two months of the year [117]. In China and other big economies, the construction sector suffered a serious impact from the COVID-19 outbreak. In view of this situation, GlobalData3 adjusted its estimate for construction growth in 2020 down from $3.1 \%$ to $0.5 \%$ [118].

The damage caused by the COVID-19 pandemic means that future asset renewal and hotel investment will focus more on the cash flow control and return on investment to maximize operating value and the value of a property [119]. Over the past 40 years, China has been developing at very high speed with a growing number of luxury hotels as a related outcome. With hotel investors suffering from significant pandemic-related losses, their future projects will be more return-driven and rational. Previously focused on big and comprehensive, investors will move to small and exquisite [120] and maximum possible revenue per square meter per minute will become the main return-optimization formula [121]. In the age of digital transformation, hotels have invested in computerized customer relationship management to make their customer service configurable and traceable and achieve the ability to improve membership conversion, provide customized services, predict the individual preference, and engage customers in ways that increase their loyalty. Revenue management and big data offer hotels ways to perform precision marketing by analyzing the travel distance of the target consumer, composition, and demand [122].

Due to the coronavirus pandemic, construction-related gross value added (GVA) is expected to shrink by $15-34 \%$ and employment by $11-25 \%$ in India because of a decrease of $13-30 \%$ in construction-related investment. This pandemic is expected to reduce both supply and demand in the construction sector. As a sector highly driven by infrastructure projects, construction is expected to suffer greatly faced with the loss of income, high uncertainty, dismal business, consumer sentiments, and the fact that government funding will remain focused on the management of COVID-19 [123,124].

\subsection{Buildings Requiring New Shapes Focusing on Technology and Smart and Green Infrastructure Initiatives}

The sustainable development goals reflect the need to maintain the same level or add more urban greenspaces open to public access, especially to marginalized groups. The importance of this goal has been emphasized by the COVID-19 pandemic. As a social and public health investment, urban public greenspaces should be considered a chance 
to balance our relationship with nature differently, looking to protect ourselves against future pandemics. Along with health benefits, such investments may also contribute to carbon sequestration, biodiversity promotion, job/food creation, and offer other beneficial effects [125].

Recovery policies, as stated by the International Energy Agency [126], should target investments in resilient and clean energy infrastructure; only then can countries avoid a rebound of emissions above pre-crisis levels, as seen after previous crises. The early stages of the COVID-19 pandemic, according to Helm [127], gave us a valuable lesson in the correlation between the decline in emissions and pollution and the decline in GDP. This correlation suggests that growing population and GDP will put our ability to meet the Paris Agreement limit of $1.5^{\circ} \mathrm{C}$ for global warming at risk. The importance of a renovation wave is stressed by Vis [128] as a necessity in our efforts to deal with this invisible pandemic [129].

As the backbone of the American economy, infrastructure is critical to the country's prosperity and the health and welfare of its people. The quality and quantity of jobs in the US economy and families' disposable income (with a loss of $\$ 3400$ for each household each year) has already suffered due to poor and outdated infrastructure. Investment in infrastructure is one way to make the pandemic-related economic burden lower for Americans in the long-term, as these investments will provide opportunities for Americans to return to work and benefit both large and small businesses. These investments will also help the economy keep moving, ensuring its speedy recovery from the pandemic-related economic shock [130].

Faced with unprecedented pressure caused by the COVID-19 pandemic and its adverse effects on budgets, US mayors should focus on infrastructure, with an emphasis on technology, as a means to give new energy to their local economy while keeping the spread of the disease in check. Despite the move to virtual and online services, investment in buildings/facilities is still necessary and should be a top long-term investment priority. The use of commercial buildings should take new forms with a focus on technology and smart infrastructure initiatives. The sense of urgency induced by the pandemic and the desire to curb the spread of the virus will make this a priority for many. Although these priorities, on the whole, look similar, investing in renewable energy solutions is a notable exception among long-term investment priorities. Mayors should make the creation of 'workforce of the future' jobs, smart technology deployment, and investment in the expansion of virtual/online city services their priority. The investment priorities for facilities and buildings are focused on creating COVID-safe environments for people. Many consider the time is now right for investment in transit-related capital projects to address longer-term needs. Job creation is a possible outcome, which proves that any investment is conducive to economic recovery [131].

Epidemiologically, serendipitous office interactions are, according to Mance [132], incompatible with the pandemic regimes of social and physical distancing. Offices, where large numbers of people work indoors in close proximity, make the virus a significant threat [133]. Shared computers and keyboards, hot desking, shared workbenches, and other similar contemporary practices are a potentially threatening cross-contamination and breeding ground for pathogenic microorganisms, viruses among them [134-136]. This means the new COVID-19 and post-COVID-19 era challenges the now widespread practice of hot desking, open plan, shared space, co-working and ABW offices, and major changes as well as organizational investment in redesign are likely with businesses seeking to make their offices COVID-19 transmission control compliant and safe [137]. Their areas designed for staff movement, interaction and meeting, density of floor space occupancy, face-to-face workstation configurations, and promotion of staff movement within and between floor areas are all conducive to the virus spread [138,139]. If such designs persist, employers may not only face penalties for noncompliance with COVID-19 regulations, but office staff may also be unwilling to return due to the potential risk of catching COVID19 [140]. Some organizations are already investing in COVID-19-compliant offices and adopting available technological strategies. Door-free entrances, handwave, foot or voice- 
activated doors and other innovations are among the technologies being investigated or considered. Some of these technologies can also be installed in elevators. Motion-sensor technologies, meanwhile, can also be used in bathroom faucets, cupboards, and light switches to limit surfaces that multiple people touch [133,138,140-142]. Smartphone apps can be used to identify failures to comply with staff distancing rules [143]. UV lights for overnight surface disinfection, enhanced air ventilation, improved filtration and occupancy indicators, and humidity monitoring are other instances of available enhancements for building management systems. Smooth surfaces ensure more effective cleaning, and nanoseptic cupboard and door handles offer continuous antiviral, anti-bacterial, antimicrobial, self-cleaning surfaces $[138,140,144,145]$. These technologies are already available and involve capital investments that now may require immediate expenditure, even though they may have been budgeted for gradual adoption over the course of multiple years before the pandemic [144].

Another option is a major redesigning of offices along with material processual and technological innovations, as an investment in community and employee health and safety [146].

A return to pre-COVID-19 investment patterns may turn into a loss if people and businesses are no longer interested in city centers. Broadband penetration and strong digitalization can be expected to amplify any lockdown habits and trends and act as increasingly important factors in location selection. Since lockdowns have been introduced, it is natural to see very few people using public transport, but it is still difficult to predict the way fear, habits, and other behavioral factors will contribute to transport demand after the pandemic. The sustainability of physical networks is an issue that has often been neglected, and related implications for the long term are especially important [147]. In the long term, changing transport networks and urban accessibility will affect the urban form and land gradient [148].

Company policies and work culture can be expected to change after the COVID-19 outbreak $[149,150]$. The construction sector will also expand its use of automatic machines. The clients are likely to move away from the property industry and towards a range of various industries such as logistics, artificial intelligence (AI), automation, e-commerce, and others. AI will become important in the analysis of the global construction market (detailed information on vendors and competition patterns), revenue, forecasting (vertical and geographical, development model, component, and service model analysis), and growth. Another important area of AI deployment will be to predict a project's cost overruns (based on the competency level of risk mitigation, the size and type of a contract, and automation) [151]. AI can also predict emerging trends and changes in customer behavior [152]. AI-enhanced drones will monitor construction sites [124].

\section{Conclusions}

This research was conducted based on the analysis of the newest scientific knowledge taken form the Web of Science, Google Scholar, and Science Direct. Long-term pandemic impact boundaries have not been fully explored, and the consequences are thus not clear. Therefore, the information used may vary according to economic sector reflex and response to the pandemic. The real estate market is facing its first changes, however they need time to be implemented. The further pandemic observation and analysis of the response are necessary.

Many new publications on COVID-19 have appeared within the public-at-large since 2020. The effects from the pandemic hit the field of construction investment strategies in addition to many other economic sectors. Rapid changes in behavior among investors appeared during and after the pandemic, becoming apparent in the construction sector among others. Remote work sparked greater demand for larger apartments/houses that could better accommodate the combining of work and personal lives within one facility. The impact on the retail sector is an upswing in demand for warehouses. Meanwhile, the 
administrative services sector faces radical changes in demand for operational space, which consequently launches an economy involving work sphere rearrangements.

The results of this research serve to focus on the incipient changes in the real estate market, real estate development guidelines, and primary trends. The research results show that COVID-19 had an impact on investments in construction for different types of property in different ways and caused changes in investment strategy.

COVID-19 has impacted investor behavior in the construction market. Here, the evidence of such behavioral changes is presented. That COVID-19 actually influenced investment in construction is shown by this research study. It affected varying kinds of property in myriad ways. Such processes affected changes in strategic investment portfolios.

The analysis presented in this review is related to three hypotheses: the papers take an explicit viewpoint on pre-, intra-, and post-pandemic sustainable construction investment and real estate development (CIRED).

All three hypotheses complement each other as quantitative (see Hypothesis 1) and qualitative (Hypotheses 2 and 3) aspects of a single analysis. The three hypotheses as a whole underline the fact that national policies dealing with COVID-19 and the pandemic have an effect on the life cycle of CIRED and investor interests, while at the same time investing strategies affect the spread of COVID-19, and that all these aspects require an integrated analysis at the level of the micro-, meso-, and macro-environment.

The study integrates different methods, including the building life cycle method, environmental psychology theory, topic model, and some essentials of scientometrics, article level metrics, informetrics, bibliometrics, sentiment analysis, altmetrics, and webometrics.

This study covers research in many different countries with different outcomes when handling the COVID-19 crisis, such as the UK, Italy, China, the USA, Vietnam, etc. Studies worldwide suggest that countries fall into clusters based on the impact of the pandemic and various criteria are considered in their grouping; the Inglehart-Welzel cultural map of the world is one example. The study by Lamper et al. [153], for instance, shows a notable correlation between the number of COVID-19 cases and deaths and a country's score on the cross-cultural control/freedom dimension and the correlation demonstrates deep links between cultural factors and disease. The numbers of COVID-19 cases and deaths are considerably higher in countries scoring high on freedom (mostly advanced economies), in contrast to more control-oriented countries with fewer COVID-19 cases and deaths. With a high freedom score, a country can be expected to score high on individualism, self-actualization, and autonomy as well, while high control scores are accompanied by high survival, embeddedness, and collectivism scores [153].

The representativeness of databases regarding scientific activity are considerably responsible for the validity of bibliometric analyses [154]. Still, Hicks [155] concludes that these databases do not entirely accurately indicate research practices in social sciences and arts and humanities due to the local nature of research and communications practices in these fields. When high comprehensiveness levels are targeted, Martínez-Gómez [156] believes that full representativeness may not be achieved for the field. The importance of sample selections in bibliometric studies is a highlight of the work by Pech and Delgado [157], along with the bias of period representativeness pertinent to various selections of the "most impactful papers". The same sort of situation also appears in our study when selecting unifying research tools. These tools enable users to search for different terms and different data across categories and analyze database information in a timely manner. It is possible that the limitations of the employed search engine might negatively impact the accuracy and representativeness of bibliometric analyses. There may be quantitative or qualitative differences between Elsevier Scopus, Google Scholar, and Clarivate Analytics' Web of Science pertinent to citation counts for a publication depending on a study's field of discipline [158-160] as well as the journals [161] and years [162] in which they were published. Furthermore, these search engines $[159,163]$ might not cover certain publications. Some imbalance in the representativeness of our research may have appeared due to the limitation involved in only researching Elsevier's Scopus, Google Scholar, and Clarivate 
Analytics' Web of Science. Therefore, other reliable and credible information sources, such as, e.g., American Society of Civil Engineers, Real Capital Analytics, and others were included in this analysis in our endeavor to improve the representativeness of the articles under analysis.

There is in-depth coverage regarding the accuracy and representativeness of the large data sets used in our bibliometric and informetric approaches. The rigor required for proper understanding of the data presented may involve more than simple counting and correlation analyzes. Thus, we supplementally employed text analyses (see Chapters 3-6).

The average compatibility of a number is $>0.7$. This means that all the results adequately reflect the construct under analysis, i.e., the sustainable construction investment. Thus, it can be claimed that the research results are reliable.

This proves the sufficiency of the accuracy and representativeness of the bibliometric and informetric approaches pertinent to our integrated, qualitative, and quantitative study.

The present study will make a substantial impact on future CIRED-related research by other authors, serving as a methodological basis for such research. The reliability of this study in the context of correlations between the selected topics and keywords confirms that.

The shortcoming of this research is that only certain nations influenced by COVID-19 were covered in the reviewed literature, which means other affected parts of the world, especially countries with highly vulnerable sustainable construction investment, remained outside of its scope. This review, however, looks over proposed policies to outline certain key guidelines for the CIRED research community and related sectors.

No detailed investigations have been done to date on the way COVID-19 and national pandemic-related policies affect CIRED and the interests of investors. The way CIRED strategies affect the spread of COVID-19 has not been examined either. Another finding is that a significant improvement in the effectiveness of CIRED analysis can be achieved by integrating the analysis of the life cycle of CIRED, the investors (each with their own goals), the pandemic circumstances, and the micro-, meso-, and macro-situation. We aim to fill the gap in understanding around pre-, intra-, and post-pandemic CIRED.

Although still limited, research on the relationship between COVID-19 and CIRED is a promising, quickly developing area with the body of investigation ever increasing. This review of selected studies aims to overview the research on the way CIRED developed during the pandemic, with the response of the real estate and construction sector as its main focus. The papers mentioned in this review were chosen based on various sustainable construction investment and real estate development trends (see Figure 1) focusing on the pre-, intra-, and post-pandemic period.

A number of issues can affect CIRED and the choice of locations. The interactions between COVID-19, national CIRED policies, and the behavior of investors as key aspects regarding CIRED requirements is what distinguishes the research findings presented in this paper, which presents an analysis that could serve various investors involved in CIRED decision-making with a view to relevant circumstances and needs at the micro-, meso-, and macro-level.

Worthwhile evidence with abundant clarifications and proposals was found in the studies accessed for this research. The findings can benefit all CIRED stakeholders.

Faced with the pandemic, the real estate and construction sector experienced many issues, and the issues are expected to persist for a long time. The entire CIRED concept must be reconsidered. The way each element influences others must be understood before pandemic policies and responses can be analyzed. The outcomes of real estate and construction development and their coordination is another area of policies that are of concern during the pandemic. Many countries around the world have now been living with lockdowns-sometimes milder, sometimes stricter-for over a year, and all life's functions have effectively moved to people's homes, where people now sleep, eat, work, exercise, and socialize most of the time. Only one outcome is possible: we need larger living spaces surrounded by greenery. Any CIRED design strategy should see this point as a key goal. 
The analysis of research articles shows a significant shift in investor preference caused by the COVID-19 pandemic with CIRED choices moving towards improved health and wellbeing outcomes for people.

The current study is different from the available most advanced studies on pre-, intra-, and post-pandemic CIRED and has two innovative elements. First, it looks at the way pandemic-related national policies affect CIRED and the interests of investors and the way investing strategies affect the spread of COVID-19. Second, this investigation suggests that an integrated look at the life cycle of CIRED, the investors, the pandemic context, and the micro-, meso-, and macro-environment as a whole significantly improves the effectiveness of CIRED analysis.

Research on how tripartite exchanges amongst pandemics, certain national policies, and business investment strategies impact sustainable construction investment is fragmented. A complete examination is, therefore, essential for improved perception of the three constituents.

This article discusses pre-, intra-, and post-pandemic CIRED at the micro-level (building), meso-level (organization) and macro-level (city, country), and looks at the related CIRED policy responses.

The continuous, three-way process of intra- and post-pandemic interactions between COVID-19, CIRED (at the micro- and meso-level), and national CIRED policies (the macrolevel) was analyzed. The study focuses on the way COVID-19 and national policies affect CIRED and the interests of investors. Another focus of this research is the way investing strategies affect the spread of COVID-19 (see Figure 1). The subjective and objective factors of CIRED and the interests of investors are considered in the analysis.

There has been a growth in the number of publications since 2020 about COVID19. The pandemic situation influenced many fields, including investment in sustainable construction. During the pandemic, the behavior of investors changed rapidly, and it can be seen in the construction sector. For the housing sector, there was an increase in the demand for larger apartments/houses due to remote work. In the retail sector, there was a higher demand for warehouses. In the office sector, there is a huge change in demand of space and rearrangement of workplaces.

This work contributes to the analysis of changes in sustainable construction investment and real estate development. This is to help investors and project developers draw attention to future changes in the process of designing and planning buildings. This is also to launch debates on designing guidelines to influenced by COVID-19 dealing with aspects like the life cycle of building development. It is necessary to follow the incipient changes and analyze potential trends as the micro-, meso-, and macro environment is constantly changing, while trends are uncertain over time.

A comprehensive description of CIRED policy implications is presented in Sections 3-6. We suggest the use of the information on the way the pandemic and COVID-19-related national policies affect CIRED and the interests of investors and on the way investing strategies affect the diffusion of COVID-19 in practical investment processes. Another suggestion is a continuous analysis of the life cycle of CIRED, the investors, the pandemic circumstances, and the micro-, meso-, and macro-context as a whole.

In the future, we are planning to continue our research by analyzing many countries according to their success indicators $[129,130]$ and calculating the emotional, hedonic, customer-perceived, and other [164-167] values of construction investments. Further multidisciplinary examination is essential to have an integrated picture of the interplay between the pandemic, national CIRED plans, and the behavior of investors and their demands for CIRED.

Author Contributions: Conceptualization, A.K. and E.K.Z.; methodology, A.K., E.K.Z., and S.R.; formal analysis, N.L., S.R., I.V., K.D., and I.U.; investigation, K.D. and I.U.; data curation, S.R. and N.L.; writing—original draft preparation, A.K., N.L., S.R., and K.D.; writing-review and editing, E.K.Z.; visualization, I.V. and I.U.; supervision, A.K. and E.K.Z. All authors have read and agreed to the published version of the manuscript. 
Funding: This research received no external funding.

Informed Consent Statement: Not applicable.

Data Availability Statement: Summary data tables are obtainable in the manuscript. The authors can deliver the applied raw data used for obtaining the conclusions in this paper to others upon request.

Acknowledgments: This work was supported by Project No. 598746-EPP-1-2018-1-LT-EPPKA2CBHE-JP “Integrating Education with Consumer Behaviour Relevant to Energy Efficiency and Climate Change at the Universities of Russia, Sri Lanka and Bangladesh" (BECK) and Project No. 2020-1-LT01-KA203-078100 "Minimizing the influence of coronavirus in a built environment" (MICROBE) from the European Union's Erasmus+ programme.

Conflicts of Interest: The authors declare no conflict of interest. The founding sponsor had no role in the design of the study or in the collection, analyzes, or interpretation of data. There was no conflicting participation in the writing of the manuscript or in the decision to publish the results.

\section{References}

1. Bansal, D.; Singh, R.; Sawhney, R.L. Effect of construction materials on embodied energy and cost of buildings-A case study of residential houses in India up to $60 \mathrm{~m}^{2}$ of plinth area. Energy Build. 2014, 69, 260-266. [CrossRef]

2. McAuley, B.; Behan, A. Improving the Sustainability of the Built Environment by Training Its Workforce in More Efficient and Greener Ways of Designing and Constructing Through the Horizon 2020 BIMcert Project. 2019. Available online: https: //arrow.tudublin.ie/schmuldistcon/28/ (accessed on 5 May 2021).

3. Petri, I.; Kubicki, S.; Rezgui, Y.; Guerriero, A.; Li, H. Optimizing energy efficiency in operating built environment assets through building information modeling: A case study. Energies 2017, 10, 1167. [CrossRef]

4. Garshasbi, S.; Santamouris, M. Using advanced thermochromic technologies in the built environment: Recent development and potential to decrease the energy consumption and fight urban overheating. Sol. Energy Mater. Sol. Cells 2019, 191, 21-32. [CrossRef]

5. The German Construction Industry must Act now to Gear Up for an Uncertain Future and be in a Position to Shape It Actively. Available online: https://www.rolandberger.com/en/Insights/Publications/What-the-new-normal-could-look-likein-construction.html (accessed on 14 April 2021).

6. General Economic Overview. Available online: https:// fiec-statistical-report.eu/european-union (accessed on 5 February 2021).

7. Short-Term Indicators Construction Industry. Deutsches Statistisches Bundesamt, 2021. Available online: https://www.destatis. de/EN/Themes/Economy/Short-Term-Indicators/Construction-Industry/pgw211.html (accessed on 5 February 2021).

8. De Vet, J.M.; Nigohosyan, D.; Nunez Ferrer, J.; Gross, A.K.; Kuehl, S.; Flickenschild, M. Impacts of the COVID-19 Pandemic on EU Industries. 2021. Available online: https://www.europarl.europa.eu/RegData/etudes/STUD/2021/662903/IPOL_STU(2021 )662903_EN.pdf (accessed on 23 April 2021).

9. Impacto of COVID-19 Crisis on Construction. European Commission, 2021. Available online: https:/ / ec.europa.eu/eurostat/ statisticsexplained/index.php?title=Impact_of_Covid-19_crisis_on_construction (accessed on 2 May 2021).

10. Euroconstruct Issues Forecasts for 2021-2023. KHL, 2020. Available online: https://www.khl.com/1147226.article (accessed on 23 April 2021).

11. Euroconstruct. Briefing on European Construction. August 2020. Available online: https://euroconstruct.org/ec/blog/2020_08 (accessed on 23 April 2021).

12. Benson, A. Types of Real Estate Investments. 2021. Available online: https://www.nerdwallet.com/article/investing/types-ofreal-estate-investments (accessed on 21 June 2021).

13. Tian, L.; Liang, Y.; Zhang, B. Measuring residential and industrial land use mix in the peri-urban areas of China. Land Use Policy 2017, 69, 427-438. [CrossRef]

14. Davis, G.B. How to Invest in Real Estate: 12 Types of Real Estate Investments. 2021. Available online: https://sparkrental.com/ types-of-real-estate-investments / (accessed on 21 June 2021).

15. Lai, Y.; Chen, K.; Zhang, J.; Liu, F. Transformation of Industrial Land in Urban Renewal in Shenzhen, China. Land 2020, 9 , 371. [CrossRef]

16. Pina, R. How Do I Start Investing in Real Estate: A Step by Step Guide. 2021. Available online: https://www.themodestwallet. com/investing-in-real-estate/ (accessed on 21 June 2021).

17. Ustaoglu, E.; e Silva, F.B.; Lavalle, C. Quantifying and modelling industrial and commercial land-use demand in France. Environ. Dev. Sustain. 2020, 22, 519-549. [CrossRef]

18. Sandoval-Félix, J.; Castañón-Puga, M.; Gaxiola-Pacheco, C.G. Analyzing Urban Public Policies of the City of Ensenada in Mexico Using an Attractive Land Footprint Agent-Based Model. Sustainability 2021, 13, 714. [CrossRef]

19. Wojewnik-Filipkowska, A.; Rymarzak, M.; Lausberg, C. Current managerial topics in public real estate asset management. World Real Estate 2015, 4, 5-10. [CrossRef]

20. Rabiei-Dastjerdi, H.; McArdle, G.; Matthews, S.A.; Keenan, P. Gap analysis in decision support systems for real-estate in the era of the digital earth. Int. J. Digital Earth 2020, 14, 1-18. [CrossRef] 
21. Kołodziejczyk, B.; Mielcar, P.; Osiichuk, D. The concept of the real estate portfolio matrix and its application for structural analysis of the Polish commercial real estate market. Econ. Res. Ekon. Istraživanja 2019, 32, 301-320. [CrossRef]

22. Jackson, C.; White, M. Challenging traditional real estate market classifications for investment diversification. J. Real Estate Portf. Manag. 2005, 11, 307-321. [CrossRef]

23. Graham, M.; Bible, D. Classifications for commercial real estate. Apprais. J. 1992, 60, 237-246.

24. Sehgal, S.; Upreti, M.; Pandey, P.; Bhatia, A. Real estate investment selection and empirical analysis of property prices: Study of select residential projects in Gurgaon, India. Int. Real Estate Rev. 2015, 18, 523-566.

25. Hua, L. A comprehensive index model for real estate convenience based on multi-source data. J. Phys. Conf. Ser. 2021, 1865, 042142. [CrossRef]

26. Kumari, A.; Maan, V. A.; Maan, V. A Deep Learning-Based Segregation of Housing Image Data for Real Estate Application. In Congress on Intelligent Systems; Springer: Singapore, 2020; pp. 165-179. [CrossRef]

27. Renigier-Biłozor, M.; Chmielewska, A. A rating system for the real estate market. Argum. Oeconomica 2019, 2, 427-458. [CrossRef]

28. Pulsiri, N.; Vatananan-Thesenvitz, R. Improving systematic literature review with automation and bibliometrics. In Proceedings of the 2018 Portland International Conference on Management of Engineering and Technology (PICMET), Honolulu, HI, USA, 19-23 August 2018. [CrossRef]

29. Daim, T.U.; Rueda, G.; Martin, H.; Gerdsri, P. Forecasting emerging technologies: Use of bibliometrics and patent analysis. Technol. Forecast. Soc. Chang. 2006, 73, 981-1012. [CrossRef]

30. Porter, A.; Watts, R. Using the PICMET Abstracts, 1997-2005. In VantagePoint Reader on your Conference CD: Tutorial. Portland International Conference on Management Engineering and Technology (PICMET'05). 2005. Available online: https: / / citeseerx.ist.psu.edu/viewdoc/download?doi=10.1.1.836.2789\&rep=rep1\&type=pdf (accessed on 25 February 2021).

31. Porter, A.L. Mining PICMET: 1997-2003 Papers Help Track You Management of Technology Developments. 2003. Available online: https: / / ieeexplore.ieee.org/document/1222794?denied= (accessed on 12 March 2021).

32. Pilkington, A. Technology commercialisation: Patent portfolio alignment and the fuel cell. In Proceedings of the PICMET'03: Portland International Conference on Management of Engineering and Technology Technology Management for Reshaping the World, Portland, OR, USA, 24-24 July 2003; pp. 400-407. [CrossRef]

33. Pilkington, A.; Teichert, T. Conceptualizing the Field of Technology Management. In In Proceedings of the Portland International Conference on Management of Engineering and Technology; Available online: https://www.pomsmeetings.org/ ConfProceedings/004/PAPERS/004-0186.pdf (accessed on 24 April 2021).

34. Hood, W.W.; Wilson, C.S. The literature of bibliometrics, scientometrics, and informetrics. Scientometrics 2001, 52, 291-314. [CrossRef]

35. Thelwall, M.; Vaughan, L.; Björneborn, L. Webometrics. Ann. Rev. Inf. Sci. Technol. 2005, 39, 81-135. [CrossRef]

36. Björneborn, L.; Ingwersen, P. Toward a basic framework for webometrics. J. Am. Soc. Inf. Sci. Technol. 2004, 55, 1216-1227. [CrossRef]

37. Thelwall, M. Webometrics: Emergent or Doomed? Inf. Res. Int. Electron. J. 2010, 15, n4.

38. Fenner, M. What can article-level metrics do for you? PLoS Biol 2013, 11, e1001687. [CrossRef] [PubMed]

39. Tóth, I.; Lázár, Z.I.; Varga, L.; Járai-Szabó, F.; Papp, I.; Florian, R.V.; Ercsey-Ravasz, M. Mitigating ageing bias in article level metrics using citation network analysis. J. Informetr. 2021, 15, 101105. [CrossRef]

40. Haustein, S. Grand challenges in altmetrics: Heterogeneity, data quality and dependencies. Scientometrics 2016, 108, 413-423. [CrossRef]

41. Priem, J. Altmetrics. Beyond Bibliometrics: Harnessing Multidimensional Indicators of Performance; Cronin, B., Sugimoto, C.R., Eds.; MIT Press: Cambridge, MA, USA, 2014; pp. 263-287.

42. Priem, J.; Taraborelli, D.; Groth, P.; Neylon, C. Altmetrics: A Manifesto. 2010. Available online: https://digitalcommons.unl.edu/ cgi/viewcontent.cgi?article=1187\&context=scholcom (accessed on 18 February 2021).

43. Weller, K. Social Media and Altmetrics: An Overview of Current Alternative Approaches to Measuring Scholarly Impact. Incent. Perform. 2015, 261-276. Available online: https://link.springer.com/content/pdf/10.1007\%2F978-3-319-09785-5_16.pdf (accessed on 4 April 2021).

44. Qiu, J.; Zhao, R.; Yang, S.; Dong, K. Informetrics: Theory, Methods and Applications; Springer: Singapore, 2017.

45. Egghe, L. Expansion of the Field of Informetrics: Origins and Consequences. Inf. Process. Manag. 2005, 41, 1311-1316. [CrossRef]

46. Guo, W.; Wu, S.; Wang, L.; Tan, T. Social-relational Topic Model for Social Networks. In Proceedings of the 24th ACM International on Conference on Information and Knowledge Management, 2015; pp. 1731-1734. Available online: https: / / dl.acm.org/doi/abs/10.1145/2806416.2806611 (accessed on 14 March 2021).

47. Rao, Y.; Li, Q.; Wenyin, L.; Wu, Q.; Quan, X. Affective topic model for social emotion detection. Neural Netw. 2014, 58, 29-37. [CrossRef] [PubMed]

48. Vollset, S.E.; Goren, E.; Yuan, C.W.; Cao, J.; Smith, A.E.; Hsiao, T.; Bisignano, C.; Azhar, G.S.; Castro, E.; Chalek, J.; et al. Fertility, mortality, migration, and population scenarios for 195 countries and territories from 2017 to 2100: A forecasting analysis for the Global Burden of Disease Study. Lancet 2020, 396, 1285-1306. [CrossRef]

49. Ezeh, A.; Kissling, F.; Singer, P. Why sub-Saharan Africa might exceed its projected population size by 2100. Lancet 2020, 396, 1131-1133. [CrossRef] 
50. Xia, C.; Hu, S.; Xu, X.; Zhao, X.; Qiao, Y.; Broutet, N.; Canfell, K.; Hutubessy, R.; Zhao, F. Projections up to 2100 and a budget optimisation strategy towards cervical cancer elimination in China: A modelling study. Lancet Public Health 2019, 4, e462-e472. [CrossRef]

51. Aletras, N.; Stevenson, M. Evaluating Topic Coherence Using Distributional Semantics. In Proceedings of the 10th International Conference on Computational Semantics (IWCS), Potsdam, Germany, 19-22 March 2013; pp. 13-22. Available online: https: //www.aclweb.org/anthology/W13-0102.pdf (accessed on 4 February 2021).

52. Newman, D.; Lau, J.; Grieser, K.; Baldwin, T. Automatic evaluation of topic coherence. In Proceedings of the Human Language Technologies: The 2010 Annual Conference of the North American Chapter of the Association for Computational Linguistics, Stroudsburg, PA, USA, 2-4 June 2010; pp. 100-108. Available online: https://www.aclweb.org/anthology/N10-1012.pdf (accessed on 11 April 2021).

53. Harris, Z.S. Distributional Structure. Word 1954, 10, 146-162. [CrossRef]

54. Chang, J.; Gerrish, S.; Wang, C.; Blei, D.M. Reading Tea Leaves: How Humans Interpret Topic Models. In Proceedings of the 23rd Annual Conference on Neural Information Processing Systems, Vancouver, BC, Canada, 7-10 December 2009; pp. 288-296. Available online: https: / / citeseerx.ist.psu.edu/viewdoc/download?doi=10.1.1.436.5683\&rep=rep1\&type=pdf (accessed on 21 February 2021).

55. White, M.D.; Marsh, E.E. Content analysis: A flexible methodology. Libr. Trends 2006, 55, 22-45. [CrossRef]

56. Sonn, J.W.; Lee, J.K. The smart city as time-space cartographer in COVID-19 control: The South Korean strategy and democratic control of surveillance technology. Eurasian Geogr. Econ. 2020, 61, 482-492. [CrossRef]

57. Sonn, J.W.; Kang, M.; Choi, Y. Smart city technologies for pandemic control without lockdown. Int. J. Urban Sci. 2020, $24,149-151$. [CrossRef]

58. Ibarra-Vega, D. Lockdown, one, two, none, or smart. Modeling containing covid-19 infection. Concept. Model. Sci. Total Environ. 2020, 730, 138917. [CrossRef]

59. Yang, S.; Chong, Z. Smart City Projects Against COVID-19: Quantitative Evidence from China. Sustain. Cities Soc. 2021, 70, 102897. [CrossRef] [PubMed]

60. Garel, A.; Petit-Romec, A. Investor rewards to environmental responsibility: Evidence from the COVID-19 crisis. J. Corp. Financ. 2021, 68, 101948. [CrossRef]

61. Ebekozien, A.; Aigbavboa, C. COVID-19 recovery for the Nigerian construction sites: The role of the fourth industrial revolution technologies. Sustain. Cities Soc. 2021, 69, 102803. [CrossRef]

62. Barlas, A.B.; Castañeda, M.P.; Güler, S.; Orkun Isa, B.; Ortiz, A.; Salazar, S.A.; Rodrigo, T.; Vazquez, S. Big Data Analysis. Investment in Real Time and High Definition. Repositorio Comillas, 2020. Available online: https://repositorio.comillas.edu/ xmlui/handle/11531/51161 (accessed on 22 January 2021).

63. Understanding Real Estate Asset Classes and Property Types. Yieldstreet. 2021. Available online: https:/ /www.yieldstreet.com/ resources/article/understanding-real-estate-asset-classes-and-property-types (accessed on 17 March 2021).

64. Dodge Momentum Index Increases in September. 2020. Available online: https://www.construction.com/news/dodgemomentum-index-increases-september-2020 (accessed on 16 March 2021).

65. Sinai, T. Commercial Real Estate: What to Invest in Today. Wharton's Real Estate Department, 28 September 2020. Available online: https:// knowledge.wharton.upenn.edu/article/commercial-real-estate-invest-today/ (accessed on 23 May 2021).

66. WPS Insights: Demand for Office Space. How Will Covid-19 Change Demand for Office Space? 2021. Available online: https:/ / www.wsp.com/en-GL/insights/how-will-covid-19-change-demand-for-office-space (accessed on 15 March 2021).

67. Karadima, S. Rethinking Office Space in a Post-Covid Environment. Investment Monitor. 2021. Available online: https: //investmentmonitor.ai/it-outsourcing/rethinking-office-space-in-a-post-covid-environment (accessed on 17 March 2021).

68. Roy, S.; Dutta, R.; Ghosh, P. Recreational and philanthropic sectors are the worst-hit US industries in the COVID-19 aftermath Soc. Sci. Humanit. Open 2021, 3, 100098. [CrossRef]

69. Pancho Vallespin, B.E.; Lopez De Guzman, D.; Nayat Young, M. Analysis of US REIT Portfolio Performance on Pre and During COVID-19 Pandemic. In Proceedings of the 2021 The 2nd International Conference on Industrial Engineering and Industrial Management, 2021; pp. 25-31. Available online: https:/ / covid19.elsevierpure.com/en/publications/analysis-of-usreit-portfolio-performance-on-pre-and-during-covid (accessed on 23 March 2021).

70. Nanda, A.; Xu, Y.; Zhang, F. How would the COVID-19 pandemic reshape retail real estate and high streets through acceleration of E-commerce and digitalization? J. Urban Manag. 2021. [CrossRef]

71. Pagano, M.S.; Sedunov, J.; Velthuis, R. How did retail investors respond to the COVID-19 pandemic? The effect of Robinhood brokerage customers on market quality. Financ. Res. Lett. 2021, 101946. [CrossRef]

72. Tanrivermiş, H. Possible impacts of COVID-19 outbreak on real estate sector and possible changes to adopt: A situation analysis and general assessment on Turkish perspective. J. Urban Manag. 2020, 9, 263-269. [CrossRef]

73. Del Giudice, V.; De Paola, P.; Del Giudice, F.P. COVID-19 infects real estate markets: Short and mid-run effects on housing prices in Campania region (Italy). Soc. Sci. 2020, 9, 114. [CrossRef]

74. Wang, H.; Wang, Q.; Sheng, X. Does Corporate Financialization Have a Non-Linear Impact on Sustainable Total Factor Productivity? Perspectives of Cash Holdings and Technical Innovation. Sustainability 2021, 13, 2533. [CrossRef]

75. Mushir, N.; Suryavanshi, R. Impact of COVID-19 on portfolio allocation decisions of individual investors. J. Pub. Aff. 2021, 13, e2649. [CrossRef] 
76. Cole, H.V.; Mehdipanah, R.; Gullón, P.; Triguero-Mas, M. Breaking Down and Building Up: Gentrification, Its drivers, and Urban Health Inequality. Curr. Environ. Health Rep. 2021, 8, 157-166. [CrossRef]

77. Hoesli, M.; Malle, R. Commercial Real Estate Prices and Covid-19. Swiss Financ. Inst. Res. Pap. 2021. [CrossRef]

78. Wang, C.N.; Nguyen, T.L.; Dang, T.T. Analyzing operational efficiency in real estate companies: An application of GM (1, 1) And DEA malmquist model. Mathematics 2021, 9, 202. [CrossRef]

79. Cheung, K.S.; Yiu, C.Y.; Xiong, C. Housing Market in the Time of Pandemic: A Price Gradient Analysis from the COVID-19 Epicentre in China. J. Risk Financ. Manag. 2021, 14, 108. [CrossRef]

80. Qian, X.; Qiu, S.; Zhang, G. The impact of COVID-19 on housing price: Evidence from China. Financ. Res. Lett. 2021, 101944. [CrossRef]

81. De Toro, P.; Nocca, F.; Buglione, F. Real Estate Market Responses to the COVID-19 Crisis: Which Prospects for the Metropolitan Area of Naples (Italy)? Urban Sci. 2021, 5, 23. [CrossRef]

82. Blakeley, G. Financialization, real estate and COVID-19 in the UK. Community Dev. J. 2021, 56, 79-99. [CrossRef]

83. Silow-Carroll, S.H.A.R.O.N.; Peartree, D.; Tucker, S.; Pham, A. Evidence on Single-Resident Rooms to Improve Personal Experience and Public Health. Health Management Associates, 2021. Available online: https:/ /www.healthmanagement.com/ wp-content/uploads/HMA.Single-Resident-Rooms-3.22.2021_final.pdf (accessed on 3 May 2021).

84. Tan, Z.; Zheng, S.; Palacios, J.; Hooks, C. Market Adoption of Healthy Buildings in the Office Sector: A Global Study from the Owner's Perspective. MIT Center for Real Estate Research Paper, (21/07). 2021. Available online: https://papers.ssrn.com/sol3 /papers.cfm?abstract_id=3784793 (accessed on 17 April 2021).

85. Diming, C.; Harris, R.; Kane, C.; Luff, M.; Muir, G.; Rischbieth, A.; Semple, E.; Todorova, A.; Waters, C.; Anastassiou, E. Fresh perspectives on the future of the office: A way forward. Corp. Real Estate J. 2021, 10, 271-284.

86. Billio, M.; Varotto, S. A New World Post COVID-19: Lessons for Business, the Finance Industry and Policy Makers; Venezia Edizioni Ca'Foscari-Digital Publishing: Venezia, Italy, 2020. [CrossRef]

87. Wójcik, D.; Ioannou, S. COVID-19 and Finance: Market Developments So Far and Potential Impacts on the Financial Sector and Centres. Tijdschr. Voor Econ. En Soc. Geogr. 2020, 111, 387-400. [CrossRef]

88. Francke, M.; Korevaar, M. Housing markets in a pandemic: Evidence from historical outbreaks. J. Urban Econ. 2021, $123,103333$. [CrossRef]

89. Cheng, J.; Wang, Y.; Xu, A.; Xia, N.; Yao, T. The COVID-19 Effect on Chinese Real Estate Market. Front. Econ. Manag. 2021, 2, 75-80. [CrossRef]

90. Jovanović-Milenković, M.; Đurković, A.; Vučetić, D.; Drašković, B. The impact of covid-19 pandemic on the real estate market development projects. Eur. Proj. Manag. J. 2020, 10, 36-49. [CrossRef]

91. Nicola, M.; Alsafi, Z.; Sohrabi, C.; Kerwan, A.; Al-Jabir, A.; Iosifidis, C.; Agha, M.; Agha, R. The socio-economic implications of the coronavirus pandemic (COVID-19): A review. Int. J. Surg. 2020, 78. [CrossRef]

92. Marona, B.; Tomal, M. The COVID-19 pandemic impact upon housing brokers' workflow and their clients' attitude: Real estate market in Krakow. Entrep. Bus. Econ. Rev. 2020, 8, 221-232. [CrossRef]

93. Gupta, A.; Peeters, J.; Mittal, V.; Van Nieuwerburgh, S. Flattening the Curve: Pandemic-Induced Revaluation of Urban Real Estate. SSRN Electron. J. 2021. [CrossRef]

94. Carson, S.; Nanda, A.; Thanos, S.; Valtonen, E.; Xu, Y. Imagining a post-COVID-19 world of real estate. Town Plan. Rev. 2021, 92, 371-376. [CrossRef]

95. Belk, R.W. Post-pandemic consumption: Portal to a new world? Cad. EBAPE BR 2020, 18, 639-647. [CrossRef]

96. D'alessandro, D.; Gola, M.; Appolloni, L.; Dettori, M.; Fara, G.M.; Rebecchi, A.; Settimo, G.; Capolongo, S. COVID-19 and living space challenge. Well-being and public health recommendations for a healthy, safe, and sustainable housing. Acta Biomedica 2020, 91, 61-75. [CrossRef] [PubMed]

97. Fernandes, N. Economic Effects of Coronavirus Outbreak (COVID-19) on the World Economy. IESE Business School Working Paper No. WP-1240-E 2020. Available online: https:/ / papers.ssrn.com/sol3/papers.cfm?abstract_id=3557504 (accessed on 19 March 2021).

98. Dolnicar, S.; Zare, S. COVID19 and Airbnb—Disrupting the Disruptor. Ann. Tour. Res. 2020, 83, 102961. [CrossRef]

99. Barua, S. Understanding Coronanomics: The Economic Implications of the Coronavirus (COVID-19) Pandemic. SSRN Electron. J. 2020. [CrossRef]

100. Balemi, N.; Füss, R.; Weigand, A. COVID-19's impact on real estate markets: Review and outlook. Financ. Mark. Portf. Manag. 2021, 1-19. [CrossRef]

101. Gujral, V.; Palter, R.; Sanghvi, A.; Vickery, B. Commercial Real Estate must Do More than Merely Adapt to Coronavirus. McKinsey \& Company. Private Equity \& Principal Investors Practice. 2020. Available online: https://magnify.partners/wp-content/ uploads / 2020/06/Commercial-real-estate-must-do-more-than-merely-adapt-to-coronavirus.pdf (accessed on 13 March 2021).

102. Awada, M.; Becerik-Gerber, B.; Hoque, S.; O’Neill, Z.; Pedrielli, G.; Wen, J.; Wu, T. Ten questions concerning occupant health in buildings during normal operations and extreme events including the COVID-19 pandemic. Build. Environ. 2021, 188, 107480. [CrossRef]

103. Oyedeji, J.O. The Impact of COVID-19 on Real Estate Transaction in Lagos, Nigeria. Int. J. Real Estate Stud. INTREST 2020, 14, 107-112. 
104. Apergis, N. The role of housing market in the effectiveness of monetary policy over the Covid-19 era. Econ. Lett. 2021, 200, 109749. [CrossRef]

105. Hromada, E. Impacts of COVID-19 on the Real Estate Market in the Czech Republic; Impacts of COVID-19 on the Real Estate Market in the Czech Republic. SHS Web Conf. 2021, 91. [CrossRef]

106. Real Capital Analytics. Global Commercial Real Estate Sales Fall Back in Q1. 2021. Available online: https://www.rcanalytics com/gct-overview-q1-2021/ (accessed on 3 May 2021).

107. Fendoglu, S.; Gan, Z.K.; Khadarina, O.; Mok, J.; Qureshi, M.; Vandenbussche, J. Commercial Real Estate. Financial Stability Risks during the Covid-19 Crisis and Beyond. International Monetary Fund, 2021. Available online: https:/ /www.elibrary.imf.org/ view/books/082/29631-9781513569673-en/ch03.xml (accessed on 3 May 2021).

108. Mundra, N.; Mishra, R.P. Business Sustainability in Post COVID-19 Era by Integrated LSS-AM Model in Manufacturing: A Structural Equation Modeling. Procedia CIRP 2021, 98, 535-540. [CrossRef]

109. Gornig, M.; Michelsen, C.; Pagenhardt, L. German construction industry remains on its path of growth during the coronavirus recession. DIW Wkly. Rep. 2021, 11, 3-13. [CrossRef]

110. Gittelsohn, J. Warehouses Lure More Cash Than Offices in Pandemic-Fueled Flip. 2020. Available online: https://www. bloomberg.com/news/articles/2020-12-10/warehouses-lure-more-cash-than-offices-in-pandemic-fueled-flip (accessed on 3 May 2021).

111. Ling, D.C.; Wang, C.; Zhou, T. A first look at the impact of COVID-19 on commercial real estate prices: Asset-level evidence. Rev. Asset Pricing Stud. 2020, 10, 669-704. [CrossRef]

112. Brodeur, A.; Gray, D.; Islam, A.; Bhuiyan, S. A literature review of the economics of COVID-19. J. Econ. Surv. 2021, in press. [CrossRef]

113. UBS. Real Estate Outlook—Edition 1. 2021. Available online: https://www.ubs.com/global/en/asset-management/insights/ asset-class-research/real-assets /2021/real-estate-outlook-edition-1.html (accessed on 3 May 2021).

114. Ding, W.; Levine, R.; Lin, C.; Xie, W. Corporate immunity to the COVID-19 pandemic. J. Financ. Econ. 2021, in press. [CrossRef]

115. Raja, S. Hotel, Retail Sectors Hit 'Hard' by Distress in Q2-RCA. 2020. Available online: https://www.spglobal.com/ marketintelligence/en/news-insights/latest-news-headlines/hotel-retail-sectors-hit-hard-by-distress-in-q2-8211-rca-595430 58 (accessed on 3 May 2021).

116. Ademmer, M.; Boysen-Hogrefe, J.; Fiedler, S.; Groll, D.; Jannsen, N.; Kooths, S.; Meuchelböck, S. German Economy Winter 2020-Second Covid Wave Interrupts Recovery. Kiel Institute Economic Outlook No. 74. 2020. Available online: https://www. econstor.eu/handle/10419/229943 (accessed on 3 May 2021).

117. Real Estate. China Property Investment Falls 16.3\%, Sales Plunge by 40\%. The Business Times, March 2020. Available online: https:/ / www.businesstimes.com.sg/real-estate/china-propertyinvestment-\%falls-163-sales-plunge-by-40(accessed on 3 May 2021).

118. GlobalData. GlobalData Sharply Revises Down Forecast for Construction Output Growth Globally to Just $0.5 \%$ in 2020.2020. Available online: https: / www.globaldata.com/globaldata-sharply-revisesdown-forecast-for\%-construction-output-growthglobally-to-just-0-5-in2020/ (accessed on 3 May 2021).

119. Lanjing Finance. Fosun and China Lodging's Hotels Accelerate Their Opening, the Hotel Industry Welcomes the Spring. 2020. Available online: https: / / www.lanjinger.com/d/134550 (accessed on 3 May 2021).

120. Qu, X. Qiu You: After the Oandemic, Investors will Prefer' Small and Refined' Mid-Range Hotels. 2020. Available online: http:/ / www.bjnews.com.cn/feature/2020/04/22/719693.html (accessed on 3 May 2021).

121. Gallen, S. The Response of Tourism Businesses vis-à-vis the Economic Ramifications of SARS-CoV-2. 2020. Available online: https:/ / www.aiest.org/news/ (accessed on 27 April 2021).

122. Hao, F.; Xiao, Q.; Chon, K. COVID-19 and China's hotel industry: Impacts, a disaster management framework, and post-pandemic agenda. Int. J. Hosp. Manag. 2020, 90, 102636. [CrossRef]

123. KPMG. COVID-19: Assessment of Economic Impact on Construction Sector in India. 2020. Available online: https://home. $\mathrm{kpmg} /$ content/dam/kpmg/in/pdf/2020/05/covid-19-assessment-economic-impact-construction-sector.pdf? (accessed on 3 May 2021).

124. Majumder, S.; Biswas, D. COVID-19 Impacts Construction Industry: Now, then and Future. In COVID-19: Prediction, DecisionMaking, and Its Impacts; Springer: Singapore, 2021; pp. 115-125. [CrossRef]

125. Geary, R.S.; Wheeler, B.; Lovell, R.; Jepson, R.; Hunter, R.; Rodgers, S. A call to action: Improving urban green spaces to reduce health inequalities exacerbated by COVID-19. Prev. Med. 2021, 145, 106425. [CrossRef] [PubMed]

126. International Energy Agency. Global Energy Review 2020. 2020. Available online: https://www.iea.org/reports/global-energyreview-2020 (accessed on 3 May 2021).

127. Helm, D. The environmental impacts of the coronavirus. Environ. Resour. Econ. 2020, 76, 21-38. [CrossRef]

128. Vis, P. Planting the Seeds of a Green Economic Recovery after COVID-19. 2020. Available online: https://www.euractiv.com/ section/energy-environment/opinion/planting-the-seeds-of-a-green-economic-recovery-after-covid-19/ (accessed on 3 May 2021).

129. Lahcen, B.; Brusselaers, J.; Vrancken, K.; Dams, Y.; Paes, C.D.S.; Eyckmans, J.; Rousseau, S. Green recovery policies for the COVID-19 crisis: Modelling the Impact on the economy and greenhouse gas emissions. Environ. Resour. Econ. 2020, 76, 731-750. [CrossRef] [PubMed] 
130. ASCE. Civil Engineers Outline Most Pressing Infrastructure Priorities for Covid-19 Relief. 2020. Available online: https: / / www.asce.org/templates/official-statement-detail.aspx?id=36882 (accessed on 3 May 2021).

131. America's Infrastructure Report Card. New Study: U.S. Mayors Prioritize Infrastructure Investment to Drive Post-COVID-19 Economic Recovery. 2020. Available online: https:/ / infrastructurereportcard.org/new-study-u-s-mayors-prioritize-infrastructureinvestment-to-drive-post-covid-19-economic-recovery/ (accessed on 3 May 2021).

132. Mance, H. The Rise and Fall of the Office. The Financial Times, 2020. Available online: https://www.ft.com/content/f43b8212-95 0a-11ea-af4b-499244625ac4(accessed on 3 May 2021).

133. Tranel, B. How should Office Buildings Change in a Post-Pandemic World? Gensler, 2020. Available online: https:/ /www.gensler. $\mathrm{com} /$ research-insight/blog/how-should-office-buildings-change-in-a-post-pandemic-world (accessed on 3 May 2021).

134. Diemar, E.L. No One will Mourn the End of Hot Desking. The Australian Human Resources Institute, 2020. Available online: https:/ / www.hrmonline.com.au/research/the-end-of-hot-desking/ (accessed on 3 May 2021).

135. Coleman, C.; Ricker, D.; Stull, J. 10 Considerations for Transitioning back to Work in a postCOVID-19 World. Gensler, 2020. Available online: https:/ / www.gensler.com/research-insight/blog/10-considerations-for-transitioning-back-to-work-in-a-post (accessed on 3 May 2021).

136. Taylor, A. Hot Desking Is Dead: Why Workers can Refuse to Return to the Office. The Age, 2020. Available online: https:/ / www.theage.com.au/business/workplace/hot-desking-is-dead-why-workerscan-refuse-to-return-to-the-office-2020 0515-p54thr.html(accessed on 3 May 2021).

137. Cummions, C.; Johanson, S. Return to the Office a Whole New Ball Game: Bring in the COVID Captain. The Age, 2020. Available online: http:/ / www.theage.com.au/business/property/return-tothe-office-a-whole-new-ball-game-bring-in-thecovid-captain-20200504-p54pn6.html?btis(accessed on 3 May 2021).

138. Morrison, R. Goodbye to the Crowded Office: How Coronavirus will Change the Way We Work Together. The Conversation, 2020. Available online: https:/ / theconversation.com/goodbye-to-the-crowdedoffice-how-coronavirus-will-change-the-waywe-work-together-137382 (accessed on 3 May 2021).

139. Bleby, M. New Digs: PwC Copies Airline Lounges, Hotels for New Melbourne Office Digs. $2020 . \quad$ Available online: https://www.afr.com/real-estate/commercial/development/new-digs-pwc-copies-airline-loungeshotels-for-newmelbourne-office-digs-20161215-gtc149 (accessed on 3 May 2021).

140. Margolies, J. What will Tomorrow's Workplace Bring? More Elbow Room for Starters. The Age, 2020. Available online: http:/ / www.theage.com.au/business/workplace-relations/what-will-tomorrow-s-wo(accessed on 3 May 2021).

141. Carmichael, S.G. Open Plan Offices will Survive this Pandemic. Here's Why. The Sydney Morning Herald. 2020. Available online: https: / / www.smh.com.au/business/workplace/openplan-offices-will-survive-this-pandemic-here-s-why-20200514 -p54st6.html (accessed on 3 May 2021).

142. Wainwright, O. Smart Lifts, Lonely Workers, no Towers or Tourists: Architecture after Coronavirus. The Guardian, 2020. Available online: https: / / www.theguardian.com/artanddesign/2020/apr/13/smart-lifts-lonely-workers-no-towers-architecture-aftercovid-19-coronavirus (accessed on 3 May 2021).

143. Kretchmer, H. 10 Ways COVID-19 could Change Office Design. World Economic Forum, 2020. Available online: https: / / www.weforum.org/agenda/2020/04/covid19-coronavirus-change-office-work-homeworking-remote-design/ (accessed on 3 May 2021).

144. Milota, C. A Common Sense Guide for Returning to the Post COVID-19 Workplace. Workdesign Magazine. 2020. Available online: https:/ / www.workdesign.com/2020/04/a-common-senseguide-for-the-return-to-the-office/ (accessed on 3 May 2021).

145. Short, S. How COVID-19 is Changing the Office. 2020. Available online: https://go.ey.com/3avJ1hf (accessed on 3 May 2021).

146. Parker, L.D. The COVID-19 Office in Transition: Cost, Efficiency and the Social Responsibility Business Case. Account. Audit. Account. J. 2020, 33, 1943-1967. [CrossRef]

147. Batty, M. The coronavirus crisis: What will the post-pandemic city look like? Environ. Plan. B Urban Anal. City Sci. 2020, 47, 547-552. [CrossRef]

148. Ahlfeldt, G.M.; Wendland, N. Fifty years of urban accessibility: The impact of the urban railway network on the land gradient in Berlin 1890-1936. Reg. Sci. Urban Econ. 2011, 41, 77-88. [CrossRef]

149. Lertpalangsunti, N.; Chan, C.W. An architectural framework for the construction of hybrid intelligent forecasting systems: Application for electricity demand prediction. Eng. Appl. Artif. Intell. 1998, 11, 549-565. [CrossRef]

150. Kaklauskas, A.; Zavadskas, E.K.; Trinkunas, V. A multiple criteria decision support on-line system for construction. Eng. Appl. Artif. Intell. 2007, 20, 163-175. [CrossRef]

151. MoneyContro. Coronavirus-Construction Sector Facing Daily Loss of Rs. 30,000 Crore Investments in Projects to Fall 13-30\%: KPMG. Available online: https:/ /www.moneycontrol.com/news/real-estate-2/coronavirus-construction-sector-facing-dailyloss-of-rs-30000-crore-investments-in-projects-to-fall-13-30-kpmg-5243761.html (accessed on 3 May 2021).

152. Banaitiene, N.; Banaitis, A. Risk management in construction projects. Risk Management-Current Issues and Challenges. In Risk Management-Current Issues and Challenges; Banaitiene, N., Ed.; VDOC.PUB: London, UK, 2012; pp. 429-448. [CrossRef]

153. Lamper, M.; Inglehart, R.; Metaal, S.; Schoemaker, H.; Papadongonas, P. Covid (2021) Pandemic Ignites Fear, but Boosts Progressive Ideals and Calls for Inclusive Economic Growth, Measuring the Pandemic's Impact on Social Values, Emotions and Priorities in 24 Countries. Glocalities, 2021. Available online: https://glocalities.com/latest/reports/valuestrends (accessed on 14 March 2021). 
154. Mongeon, P.; Paul-Hus, A. The journal coverage of bibliometric databases: A comparison of Scopus and Web of Science. Scientometrics 2016, 106, 213-228. [CrossRef]

155. Hicks, D.; Wang, J. Coverage and overlap of the new social sciences and humanities journal lists. J. Am. Soc. Inf. Sci. Technol. 2011, 62, 284-294. [CrossRef]

156. Martínez-Gómez, A. Bibliometrics as a tool to map uncharted territory: A study on non-professional interpreting. Perspectives 2015, 23, 205-222. [CrossRef]

157. Pech, G.; Delgado, C. Screening the most highly cited papers in longitudinal bibliometric studies and systematic literature reviews of a research field or journal: Widespread used metrics vs. a percentile citation-based approach. J. Informetr. 2021, $15,101161$. [CrossRef]

158. Fardi, A.; Kodonas, K.; Lillis, T.; Veis, A. Top-Cited Articles in Implant Dentistry. Int. J. Oral Maxillofac. Implant. 2017, 32, 555-564. [CrossRef] [PubMed]

159. Baldiotti, A.L.P.; Amaral-Freitas, G.; Barcelos, J.F.; Freire-Maia, J.; de França Perazzo, M.; Freire-Maia, F.B.; Paiva, S.M.; Ferreira, F.M.; Martins-Júnior, P.A. The Top 100 Most-Cited Papers in Cariology: A Bibliometric Analysis. Caries Res. 2020, 18, 1-9. [CrossRef]

160. Bakkalbasi, N.; Bauer, K.; Glover, J.; Wang, L. Three options for citation tracking: Google Scholar, Scopus and Web of Science. Biomed. Digit. Libr. 2006, 3, 1-8. [CrossRef]

161. Falagas, M.E.; Pitsouni, E.I.; Malietzis, G.A.; Pappas, G. Comparison of PubMed, Scopus, Web of Science, and Google Scholar: Strengths and weaknesses. FASEB J. 2007, 22, 338-342. [CrossRef]

162. Harzing, A.-W.K.; Van der Wal, R. Google Scholar as a new source for citation analysis. Ethics Sci. Environ. Politics 2008, 8, 61-73. [CrossRef]

163. Ahmad, P.; Asif, J.A.; Alam, M.K.; Slots, J. A bibliometric analysis of Periodontology 2000. Periodontology 2020, 82, $286-297$. [CrossRef] [PubMed]

164. Kaklauskas, A.; Herrera-Viedma, E.; Echenique, V.; Zavadskas, E.K.; Ubarte, I.; Mostert, A.; Podvezko, V.; Binkyte, A.; Podviezko, A. Multiple criteria analysis of environmental sustainability and quality of life in post-Soviet states. Ecol. Indic. 2018, 89, 781-807. [CrossRef]

165. Kaklauskas, A.; Dias, W.P.; Binkyte-Veliene, A.; Abraham, A.; Ubarte, I.; Randil, O.P.; Siriwardana, C.S.; Lill, I.; Milevicius, V.; Podviezko, A.; et al. Are environmental sustainability and happiness the keys to prosperity in Asian nations? Ecol. Indic. 2020, 119, 106562. [CrossRef]

166. Kaklauskas, A.; Abraham, A.; Milevicius, V. Diurnal emotions, valence and the coronavirus lockdown analysis in public spaces. Eng. Appl. Artif. Intell. 2021, 98, 104122. [CrossRef]

167. Kaklauskas, A.; Bardauskiene, D.; Cerkauskiene, R.; Ubarte, I.; Raslanas, S.; Radvile, E.; Kaklauskaite, U.; Kaklauskiene, L. Emotions analysis in public spaces for urban planning. Land Use Policy 2021, 107, 105458. [CrossRef] 